\title{
Shank Modulates Postsynaptic Wnt Signaling to Regulate Synaptic Development
}

\author{
(- Kathryn P. Harris, ${ }^{1,2}$ Yulia Akbergenova, ${ }^{1,2}$ Richard W. Cho, ${ }^{1,2}{ }^{-}$Maximilien S. Baas-Thomas, ${ }^{1,2}$ and ${ }^{-}$J. Troy Littleton ${ }^{1,2}$ \\ Departments of ${ }^{1}$ Biology and ${ }^{2}$ Brain and Cognitive Sciences, The Picower Institute for Learning and Memory, Massachusetts Institute of Technology, \\ Cambridge, Massachusetts 02139
}

Prosap/Shank scaffolding proteins regulate the formation, organization, and plasticity of excitatory synapses. Mutations in SHANK family genes are implicated in autism spectrum disorder and other neuropsychiatric conditions. However, the molecular mechanisms underlying Shank function are not fully understood, and no study to date has examined the consequences of complete loss of all Shank proteins in vivo. Here we characterize the single Drosophila Prosap/Shank family homolog. Shank is enriched at the postsynaptic membrane of glutamatergic neuromuscular junctions and controls multiple parameters of synapse biology in a dose-dependent manner. Both loss and overexpression of Shank result in defects in synaptic bouton number and maturation. We find that Shank regulates a noncanonical Wnt signaling pathway in the postsynaptic cell by modulating the internalization of the Wnt receptor Fz2. This study identifies Shank as a key component of synaptic Wnt signaling, defining a novel mechanism for how Shank contributes to synapse maturation during neuronal development.

Key words: postsynaptic scaffold; Shank; synaptic development; Wnt signaling

\section{Significance Statement}

Haploinsufficiency for SHANK3 is one of the most prevalent monogenic causes of autism spectrum disorder, making it imperative to understand how the Shank family regulates neurodevelopment and synapse function. We created the first animal model lacking all Shank proteins and used the Drosophila neuromuscular junction, a model glutamatergic synapse, to characterize the role of Shank at synapses. We identified a novel function of Shank in synapse maturation via regulation of Wnt signaling in the postsynaptic cell.

\section{Introduction}

The postsynaptic density (PSD) of excitatory synapses contains a complex and dynamic arrangement of proteins, allowing the cell to respond to neurotransmitter and participate in bidirectional signaling to regulate synaptic function (Sheng and Kim, 2011). Prosap/Shank family proteins are multidomain proteins that form an organizational scaffold at the PSD. Human genetic studies have implicated SHANK family genes as causative for autism spectrum disorder (ASD) (Uchino and Waga, 2013; Guilmatre et

\footnotetext{
Received Nov. 27, 2015; revised March 30, 2016; accepted April 25, 2016.

Author contributions: K.P.H., Y.A., R.W.C., and J.T.L. designed research; K.P.H., Y.A., R.W.C., and M.S.B.-T. performed research; K.P.H., Y.A., R.W.C., M.S.B.-T., and J.T.L. analyzed data; K.P.H. and J.T.L. wrote the paper.

This work was supported by National Institutes of Health (NIH) Grant MH097680 and the Simons Center for the Social Brain at the Massachusetts Institute of Technology. We thank V. Budnik for the Fz2-N and Fz2-C antisera and the UAS-myc-NLS-DFzZ-C stock, S. Sigrist for the GluRIIB-GFP stock, and G. Struhl for the UAS-Fz2-GFP fly stock. We thank the Bloomington Drosophila Stock Center (NIH Grant P400D018537), the Drosophila Genome Resource Center (NIH Grant 2P400D010949-10A1), and the Developmental Studies Hybridoma Bank (University of lowa, Department of Biology, lowa City, IA) for reagents. We thank David Yang for technical assistance.

The authors declare no competing financial interests.

Correspondence should be addressed to Kathryn P. Harris at The Picower Institute for Learning and Memory, 43 Vassar Street 46-3251, Cambridge, MA 02139. E-mail: kpharris@mit.edu.

DOI:10.1523/JNEUROSCI.4279-15.2016

Copyright $\odot 2016$ the authors $\quad 0270-6474 / 16 / 365820-13 \$ 15.00 / 0$
}

al., 2014), with haploinsufficiency of SHANK3 considered one of the most prevalent causes (Betancur and Buxbaum, 2013). Investigations of Shank in animal models have identified several functions for the protein at synapses, including regulation of glutamate receptor trafficking, the actin cytoskeleton, and synapse formation, transmission, and plasticity (Grabrucker et al., 2011; Jiang and Ehlers, 2013). However, phenotypes associated with loss of Shank are variable, and it has been challenging to fully remove Shank protein function in vivo as a result of redundancy between three Shank family genes and the existence of multiple isoforms of each Shank. There is a single homolog of Shank in Drosophila (Liebl and Featherstone, 2008), presenting the opportunity to characterize the function of Shank at synapses in vivo in null mutant animals.

Wnt pathways play important roles in synaptic development, function, and plasticity (Dickins and Salinas, 2013). Like Shank and several other synaptic genes, deletions and duplications of canonical Wnt signaling components have been identified in individuals with ASD (Kalkman, 2012). A postsynaptic noncanonical Wnt pathway has been characterized at the Drosophila glutamatergic neuromuscular junction (NMJ), linking release of Wnt by the presynaptic neuron to plastic responses in the post- 
synaptic cell. In this Frizzled-2 (Fz2) nuclear import (FNI) pathway, Wnt1/Wg is secreted by the neuron and binds its receptor $\mathrm{Fz} 2$ in the postsynaptic membrane. Surface Fz2 is then internalized and cleaved, and a C-terminal fragment of Fz2 (Fz2-C) is imported into the nucleus in which it interacts with ribonucleoprotein particles containing synaptic transcripts (Mathew et al., 2005; Ataman et al., 2006; Mosca and Schwarz, 2010; Speese et al., 2012). Mutations in this pathway result in defects of synaptic development at the NMJ.

We created a null allele of Drosophila Shank, allowing us to investigate the consequences of removing all Shank protein in vivo. We show that loss of Shank impairs synaptic bouton number and maturity and results in defects in the organization of the subsynaptic reticulum (SSR), a complex system of infoldings of the postsynaptic membrane at the NMJ. We also demonstrate that overexpression of Shank has morphological consequences similar to loss of Shank and that Shank dosage is critical to synaptic development. Finally, our results indicate that Shank regulates the internalization of $\mathrm{Fz} 2$ to affect the FNI signaling pathway, revealing a novel connection between the scaffolding protein Shank and synaptic Wnt signaling.

\section{Materials and Methods}

Drosophila stocks and transgenics. All Drosophila strains were cultured on standard media at $25^{\circ} \mathrm{C}$. The following stocks were used: mef2-GAL4 [Bloomington Drosophila Stock Center (BDSC) stock \#27390; Ranganayakulu et al., 1996], 24B-GAL4 (BDSC stock \#1767; Brand and Perrimon, 1993), UAS-NLS-GFP (BDSC stock \#4776; Shiga et al., 1996), Df(2R)BSC361 (BDSC stock \#24385; Cook et al., 2012), UAS-myc-NLSDFz2-C (Mathew et al., 2005), GluRIIB-GFP (Schmid et al., 2008), and UAS-Fz2-GFP (Chen et al., 2004). Animals of either sex were used. Full-length Shank cDNA (Drosophila Genomics Resource Center stock \#LD13733; Rubin et al., 2000) was subcloned into pENTR/DTOPO (Life Technologies). UAS-Shank and UAS-Shank-GFP were generated using the Gateway system (Invitrogen) to move Shank into destination vectors pPW and pPWG (Gateway vectors developed by T. Murphy, Carnegie Institution of Washington, Baltimore, MD). pPW and pPWG were modified with the addition of an attB sequence (Groth et al., 2004) at the Nsi1 site. The constructs were injected into a third chromosome docking strain $\left(y^{1} w^{67 c 23} ; P\{\right.$ CaryP $\left.\} a t t P 2\right)$ by Best Gene.

Shank antibody production. A Shank antibody was raised against a Shank peptide (amino acids 51-148) in rabbit using polyclonal genomic antibody technology by SDIX.

Shank mutagenesis. The Minos line Mi\{ET1\}Prosap ${ }^{\text {MB03234 }}$ (BDSC stock \#24446; Metaxakis et al., 2005; Bellen et al., 2011) carrying an insertion in the large first intron of the Shank locus was combined with the Bloom allele Blm ${ }^{N 1}$ (BDSC stock \#28878; McVey et al., 2007) to produce the stock Mi\{ET1\}Prosap ${ }^{M B 03234} ; B^{2} m^{N 1} / T M 6 B$. The Minos transposase $P[h s I L M i T] 2.4$ (BDSC stock \#24613; Metaxakis et al., 2005) was combined with the Bloom allele Blm ${ }^{D 3}$ (BDSC stock \#8656; Boyd et al., 1981) to produce the stock noc ${ }^{S c o} / S M 6 a, P[h s I L M i T] 2.4 ; B l m^{D 3} /$ TM6B. These two stocks were crossed together to mobilize the Minos insertion in a Blm mutant background as described previously (Witsell et al., 2010). Approximately 200 GFP-negative candidate lines were tested by PCR to detect deletions that reached into coding sequences (the end of the first exon and/or the start of the second exon). Shank ${ }^{D 101}$ was identified and sequenced to determine the deletion breakpoints (genomic location of the deleted sequence is 2R:14062907..14074533, FB2015_04). A precise excision with no deletion was also identified. "Control" in all figures refers to this precise excision line unless specified otherwise.

Immunostaining. Larvae were reared at $25^{\circ} \mathrm{C}$ and dissected at the third wandering instar stage. Larvae were dissected in HL3.1 solution (in mм: $70 \mathrm{NaCl}, 5 \mathrm{KCl}, 10 \mathrm{NaHCO}_{3}, 4 \mathrm{MgCl}_{2}, 5$ trehalose, 115 sucrose, and 5 HEPES, pH 7.2) and fixed in 4\% paraformaldehyde or as indicated otherwise. After washes in PBT (PBS containing 0.3\% Triton X-100), larvae were blocked for $1 \mathrm{~h}$ in PBT containing 2\% normal goal serum, incubated overnight with primary antibody at $4^{\circ} \mathrm{C}$, washed, incubated with second- ary antibodies for $2 \mathrm{~h}$ at room temperature, washed, and mounted in Vectashield (Vector Laboratories) for imaging. For Shank stainings, Shank antibody was preabsorbed on Shank null mutant tissue to reduce background staining. Antibodies were as follows: mouse anti-Dlg, 1:1000 [Developmental Studies Hybridoma Bank (DSHB) stock \#4F3; Parnas et al., 2001]; mouse anti-Bruchpilot (Brp), 1:500 (DSHB stock \#nc82; Wagh et al., 2006); mouse anti-GluRIIA, 1:200, fixed $5 \mathrm{~min}$ in ice-cold methanol (DSHB stock \#8B4D2); rabbit anti-GluRIII, 1:500 (Marrus et al., 2004); rabbit anti-GluRIII-488, 1:500 (Marrus et al., 2004; Blunk et al., 2014); anti-Fz2-C, 1:500, and anti-N-terminal fragment of Fz2 (Fz2N), 1:100, fixed $10 \mathrm{~min}$ in 4\% paraformaldehyde (Mathew et al., 2005); anti-Futsch, 1:50, fixed $30 \mathrm{~min}$ in Bouin's fixative (DSHB stock \#22C10; Fujita et al., 1982; Zipursky et al., 1984); anti-Shank, 1:2000; anti-GFP Alexa Fluor 488 conjugate, 1:500 (Life Technologies); DyLight 649 conjugated anti-horseradish peroxidase, 1:1000 (Jackson Immuno Research); and Alexa Fluor 488 goat anti-mouse, Alexa Fluor 488 goat anti-rabbit, and Alexa Fluor 546 goat anti-rabbit, 1:400 (Life Technologies). Images were acquired with a $40 \times, 1.3$ numerical aperture oilimmersion objective (Carl Zeiss).

Western blot analysis. For quantitative Western blot analysis, larvae were dissected to remove internal organs and isolate the body wall. Body walls were lysed in $1 \times$ NuPage LDS sample buffer (Life Technologies) and analyzed by SDS-PAGE. Equal loading was assayed using antitubulin. Western blots were imaged using an Odyssey infrared scanner (Li-Cor). The signal intensity for each band was measured using Image Studio (Li-Cor) and normalized to the signal intensity of tubulin. Antibodies were as follows: rabbit anti-GFP, 1:2000 (ab6556; Abcam); mouse anti-tubulin, 1:20,000 (T5168; Sigma-Aldrich); and IRDye 680LT goat anti-mouse and IRDye 800CW goat anti-rabbit (Li-Cor).

Internalization of Fz2. The antibody internalization assay was adapted from previously described procedures (Mathew et al., 2005). Briefly, samples were dissected in HL3 solution (in mM: $70 \mathrm{NaCl}, 5 \mathrm{KCl}, 20$ $\mathrm{MgCl}_{2}, 10 \mathrm{NaHCO}_{3}, 5$ trehalose, 115 sucrose, and 5 HEPES, pH 7.2) containing $0.1 \mathrm{mM} \mathrm{Ca}^{2+}$, and anti-DFz2-N was added (1:100) before incubation for $2 \mathrm{~h}$ at $4^{\circ} \mathrm{C}$. Samples were then washed at $4^{\circ} \mathrm{C}$ in HL3 containing $2 \mathrm{mM} \mathrm{Ca}^{2+}$ and shifted to room temperature for $5 \mathrm{~min}$. Samples were fixed in 4\% paraformaldehyde in HL3, washed with PBS, and incubated with Alexa Fluor 546-conjugated secondary antibody under nonpermeabilizing conditions to label external DFz2. Samples were then postfixed for $10 \mathrm{~min}$ in $4 \%$ paraformaldehyde in HL3, permeabilized with PBS containing $0.3 \%$ Triton X-100, and incubated with Alexa Fluor 488-conjugated secondary antibody.

Quantification and statistical analyses of confocal images. Analyses were conducted using Volocity (version 6.3; PerkinElmer Life and Analytical Sciences) or FIJI/ImageJ (version 2.0.0-rc-32/1.49v; Schindelin et al., 2012). Ghost boutons (GBs) were identified by the presence of a presynaptic bouton (HRP-labeled) that lacked Dlg staining in fixed preparations. Counting of boutons and GBs was conducted at hemisegment A3 at muscle $6 / 7$, and $n$ refers to the number of NMJs analyzed, with no more than two NMJs analyzed per animal. Measurements of active zone (AZ) density, GluR intensity, and bouton size were conducted on $12 \mathrm{lb}$ boutons per animal, using one terminal bouton and five adjacent nonterminal boutons, on two different branches; $n$ refers to the number of animals analyzed. Bouton size was determined by measuring the bouton diameter. AZ density was quantified manually by counting Brp-labeled puncta and dividing by the volume of HRP. GluR intensity was quantified by measuring the fluorescence intensity of GluRIII, GluRIIA, or GluRIIB signal within an ROI defined by the HRP signal, and the average intensity within the ROI was divided by the average HRP intensity. Glutamate receptor field size was quantified by manually outlining GluR-labeled fields and computing volume; $n$ refers to the number of individual GluRlabeled fields analyzed, with at least six animals analyzed per genotype. Nuclear import of Fz2-C was quantified as described previously (Mathew et al., 2005), by counting distinct spots of Fz2-C immunoreactivity over background staining in muscle nuclei. Nucleus boundaries were identified by costaining with Lamin C (DSHB stock \#LC28.26). Fz2-C counting was conducted at hemisegment $\mathrm{A} 3$ at muscle $6 / 7$, and $n$ refers to the number of nuclei counted, with data generated from at least four animals per genotype. Fz2 internalization was quantified by measuring the fluo- 
rescence intensity of surface or internalized Fz2 within an ROI defined by the HRP signal, and the average intensity within the ROI was then normalized to average HRP intensity. Images were captured from hemisegments A3 and A4 at muscle 6/7, and $n$ refers to the number of NMJs analyzed, with no more than two NMJs analyzed per animal.

Statistical analyses. Statistical significance in two-way comparisons was determined by a Student's $t$ test, whereas ANOVA was used when comparing more than two datasets. The $p$ values associated with ANOVA tests are adjusted $p$ values obtained from a Tukey's post hoc test. In all figures, the data are presented as mean $\pm \mathrm{SEM} ;{ }^{*} p<0.05,{ }^{* *} p<0.01$, and ${ }^{* * *} p<0.001$ (n.s. indicates not significant). Statistical comparisons are with control unless noted.

Electron microscopy. Samples were fixed using a Ted Pella microwave in $1 \%$ glutaraldehyde and $4 \%$ paraformaldehyde in O.1M cacodylate buffer, $\mathrm{pH}$ 7.2. The first round of microwave fixation was at $100 \mathrm{~W}$ for $1 \mathrm{~min}$ on, $1 \mathrm{~min}$ off, and $1 \mathrm{~min}$ on (Tapia et al., 2012). Fixation continued at 300 $\mathrm{W}$ for $20 \mathrm{~s}$ on, $20 \mathrm{~s}$ off, and $20 \mathrm{~s}$ on, three times. Samples were then removed from the microwave and fixed in a fresh fixative for $30 \mathrm{~min}$ at room temperature. Samples were washed in $0.1 \mathrm{M}$ cacodylate buffer and further processed as described previously (Blunk et al., 2014). Quantifications of SSR and bouton area were performed in Adobe Photoshop CS4 (Adobe Systems). SSR area was measured by manually outlining the SSR and bouton and dividing the cross-sectional SSR area by the crosssectional bouton area. SSR density was calculated by automatically outlining the SSR foldings with Photoshop Magic Wand Tool with tolerance level 10 and dividing by the SSR area. The bouton membrane commonly makes a contact with electron-dense SSR foldings. The length of regions $(>200 \mathrm{~nm})$ in which the bouton membrane was not opposed by SSR was calculated in pixels and normalized by bouton perimeter. Each $n$ value represents a single bouton, with data generated from at least three individual larvae of each genotype.

Shank alignment. The Drosophila Shank amino acid sequence was aligned with human SHANK1, SHANK2, and SHANK3 using Clustal Omega (version 1.2.1; Sievers et al., 2011).

Quantitative RT-PCR. Quantitative RT-PCR (qPCR) was performed in triplicate for each of four independent biological replicates per genotype. RNA was extracted from three adult male flies per sample using an RNeasy Mini kit (Qiagen) and treated with DNase I (Qiagen). Singlestranded cDNA was synthesized using a High Capacity cDNA reverse transcription kit (Applied Biosystems) according to the protocol of the manufacturer. Gene-specific transcription levels were determined in a 10 $\mu l$ reaction using SYBR Green Premium Ex TaqII master mix (TaKaRa) in optical 96-well plates using a LightCycler480 Real Time PCR system (Roche). Shank primers (5'-CCAAATATCCCACGGGTCCG and 5'GGAGCTGAATGTCTACAAGTGTCTGC) were designed to span the large first intron, amplifying a 212 bp product from endogenous transcript or transcript derived from the UAS-Shank transgene, and separable from genomic DNA for which the amplicon is $>21 \mathrm{~kb}$. Candidate reference genes and primers (e1F-1A, Rap21, and 14-3-3e) were selected from Ling and Salvaterra (2011). Melt curve analysis was conducted to ensure primer specificity. A calibration curve was conducted to determine primer efficiency, by performing $\mathrm{qPCR}$ with each primer pair on a twofold dilution series of control template. The slope of the resulting standard curve was used to calculate primer efficiency (efficiency $=$ $-1+10^{(-1 / \text { slope })}$; Shank, 98.0\%; e1F-1A, 98.3\%; Rap21, 99.83\%; and 14$3-3 \varepsilon, 101.78 \%)$. Reference genes were analyzed using NormFinder software (version 0.953 ) to determine expression stability (Andersen et al., 2004). elF-1A had the lowest stability value $(0.005 \pm 0.010)$ as determined by NormFinder, indicating the highest stability in gene expression among the candidates, and was selected as the reference gene for relative quantification. The $2^{-\Delta \Delta C} \tau$ method (Livak and Schmittgen, 2001) was used to compute Shank gene expression relative to the reference gene, and data are presented as expression relative to controls $\left(2^{-\Delta \Delta C} \tau\right)$.

\section{Results}

Shank localizes to the postsynaptic membrane

Drosophila Shank (CG30483) is predicted to encode a $\sim 200 \mathrm{kDa}$ protein containing several protein-protein interaction motifs, conserved from invertebrates to humans (Fig. 1A,B). To study
Shank function, we generated antisera against a peptide near the $\mathrm{N}$ terminus of the protein (Fig. $1 B$ ). We also produced a null mutant $\left(\right.$ Shank ${ }^{D 101}$; Fig. $\left.1 A\right)$ and a transgenic animal expressing the full-length cDNA under control of the UAS promoter, allowing us to assess synapse development upon loss or overexpression of Shank. Shank mutants were generated through mobilization of a Minos transposable element located in the large first intron of the Shank locus. The resulting Shank ${ }^{D 101}$ allele carries a deletion from the middle of the first intron to the $3^{\prime}$-UTR, removing $97 \%$ of the coding region of the gene. The size of the deletion, along with genetic evidence discussed below, indicates that Shank ${ }^{D 101}$ is a null allele. A precise excision without any deletion was generated from the same mutagenesis and used as a control.

Shank ${ }^{D 101}$ homozygotes survive to adulthood, allowing examination of synaptic defects at the third-instar larval NMJ. The Drosophila larval glutamatergic NMJ consists of an arbor of synaptic boutons innervating a muscle fiber. Within each bouton are numerous AZs - the sites of neurotransmitter release-that are apposed by ionotropic glutamate receptor clusters in the postsynaptic cell. Immunostaining for Shank revealed that the protein is enriched at the NMJ (Fig. 1C). The synaptic enrichment is substantially reduced in Shank ${ }^{D 101}$ animals (Fig. 1D) and enhanced on postsynaptic expression of Shank using a muscle GAL4 driver (mef2>Shank; Fig. 1E). We also detected staining of the muscle nuclei and staining throughout the muscle cytoplasm, which are unchanged in all genotypes and are thus likely to be nonspecific. Because the peptide that was used to generate the antisera is deleted by the D101 mutation, we interpret any residual staining seen in Shank ${ }^{D 101}$ animals as nonspecific to Shank. To test whether Shank localizes to the PSD as it does in mammalian neurons (Takeuchi et al., 1997), we costained for Dlg, the homolog of mammalian PSD-95 (Lahey et al., 1994). Shank and Dlg overlap at the synapse, with the Shank domain extending slightly beyond Dlg (Fig. $1 F$ ). We also examined Shank distribution by overexpressing Shank with a C-terminal GFP tag (mef2>ShankGFP; Fig. $1 G)$. As observed for the endogenous protein, ShankGFP is localized at the NMJ. Shank-GFP also decorates cytoplasmic puncta, which are not observed with the endogenous protein, and may be a consequence of overexpressing the protein.

\section{Shank regulates synapse morphology and maturity in a dose dependent manner}

To investigate how loss or overexpression of Shank affects synaptic development, we quantified the number of boutons per NMJ at muscle 6/7 in hemisegment A3. Shank ${ }^{D 101}$ animals exhibited a $24 \%$ reduction in the number of synaptic boutons compared with control animals (Fig. $2 A, B, I$; control, $1.0 \pm 0.03, n=48$; Shank $k^{D 101}, 0.76 \pm 0.03, n=36, p<0.0001$, ANOVA). We also observed an abnormally high number of structures known as GBs in Shank ${ }^{D 101}$ mutants (Fig. 2B', arrowheads). GBs are immature synaptic structures, identified as round varicosities of the presynaptic membrane that lack postsynaptic proteins such as Dlg and glutamate receptors (Ataman et al., 2006, 2008). Shank ${ }^{D 101}$ animals exhibited a fourfold increase in the average number of GBs per NMJ compared with control animals (Fig. $2 A^{\prime}, B^{\prime}, J$; control, $1.0 \pm 0.26, n=31$; Shank ${ }^{D 101}, 3.6 \pm 0.74, n=24, p=0.0268$, ANOVA). Thus, Shank is required for normal number and maturity of synaptic boutons.

When Shank ${ }^{D 101}$ was placed in trans to a chromosomal deficiency that removes the entire Shank locus, equivalent defects were observed compared with Shank ${ }^{D 101}$ homozygous animals (Fig. 2C, $C^{\prime}, I, J$; Shank ${ }^{D 101} / D f, 0.76 \pm 0.02$ boutons, $n=13, p>$ 0.9999, ANOVA; $4.49 \pm 1.09 \mathrm{GBs}, n=13, p>0.9999$, ANOVA). 


\section{A}

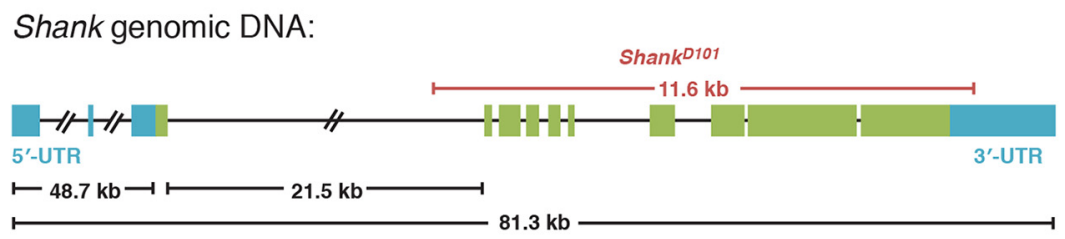

B

Shank protein:

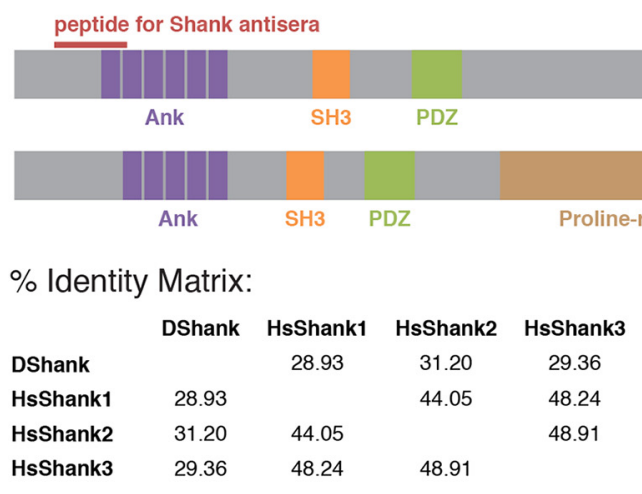
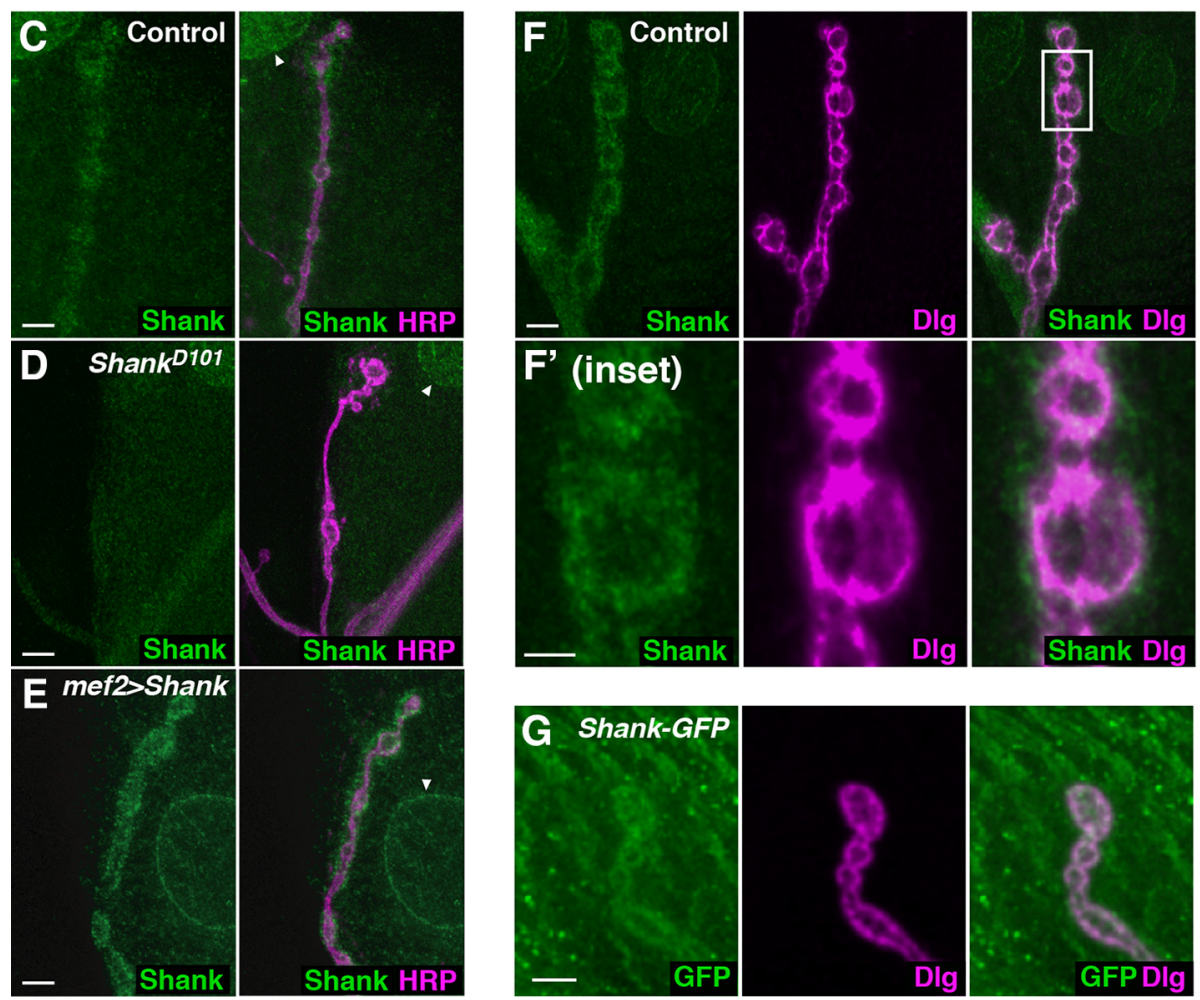

Figure 1. Shank localizes to the PSD at Drosophila NMJs. A, Genomic locus of Shank (CG30483). The region deleted in Shank ${ }^{D 101}$ is indicated in red. Coding exons are green, with noncoding exons in blue. B, The Shank locus encodes a 1871 aa protein predicted to contain Ankyrin repeats (Ank), Srchomolgy 3 (SH3), PDZ domains, and a C-terminal coiled-coil motif. The region used to generate anti-Shank antisera is indicated in red. Shank protein structure is highly conserved compared with human SHANK3. SHANK3 has a proline-rich region and C-terminal SAM domain that are not conserved in Drosophila Shank. A percentage identity matrix calculated using Clustal Omega is presented comparing Drosophila Shank and human SHANK1, SHANK2, and SHANK3. C-E, Representative NMJs, stained with antibodies to Shank (green). HRP staining (magenta) marks the neuronal membrane. Arrowheads mark nonspecific staining of the muscle nuclei, which is unchanged in all genotypes. $\boldsymbol{F}$, Representative NMJs, stained with antibodies to Shank (green) and Dlg (magenta). G, Representative NMJs of animals expressing UAS-Shank-GFP with the mef2-GAL4 driver and stained for GFP (green) and Dlg (magenta). Scale bars: $\left(-F, G, 5 \mu \mathrm{m} ; F^{\prime}, 2 \mu \mathrm{m}\right.$.

This finding is consistent with Shank ${ }^{D 101}$ being a null allele. Intriguingly, we also detected defects in animals heterozygous for Shank, with a statistically significant $15 \%$ reduction in bouton number but no increase in GBs, compared with controls (Fig.
$2 D, D^{\prime}, I, J$; Shank $k^{D 101} /+, 0.85 \pm 0.03$ boutons, $n=19, p<$ 0.0110 , ANOVA; $0.73 \pm 0.21 \mathrm{GBs}, n=18, p>0.9999$, ANOVA). Thus, loss of a single copy of Shank is sufficient to produce mild defects in synapse development. 

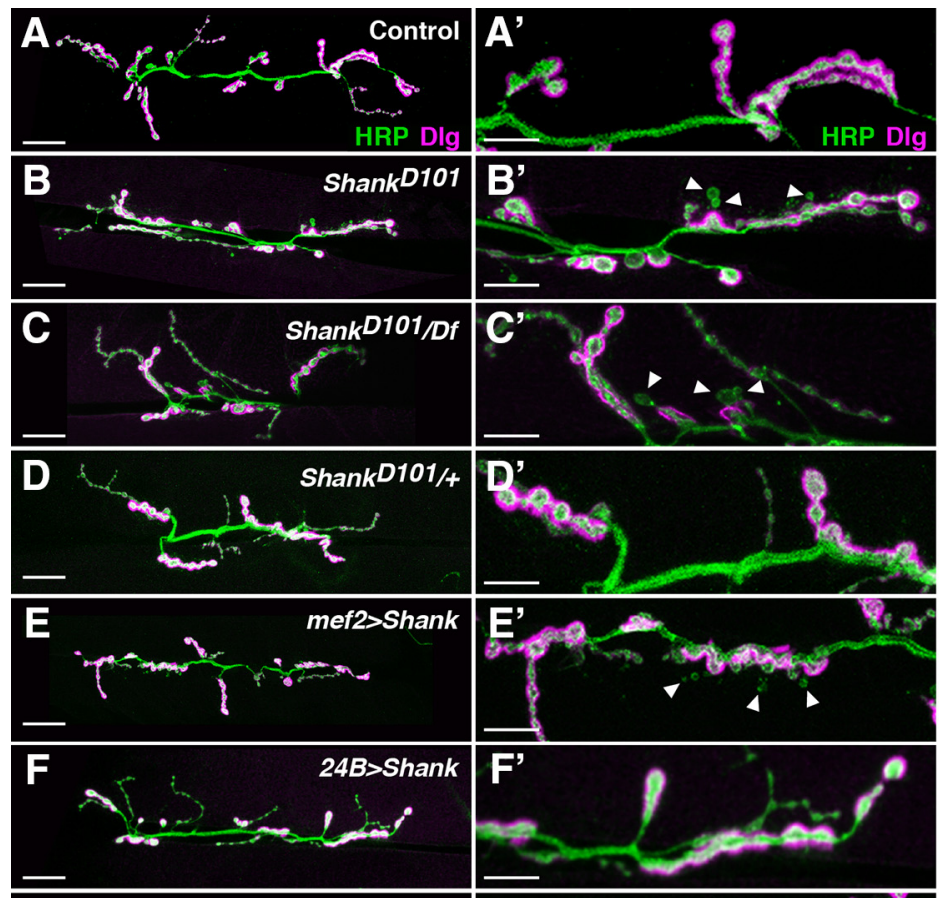

K
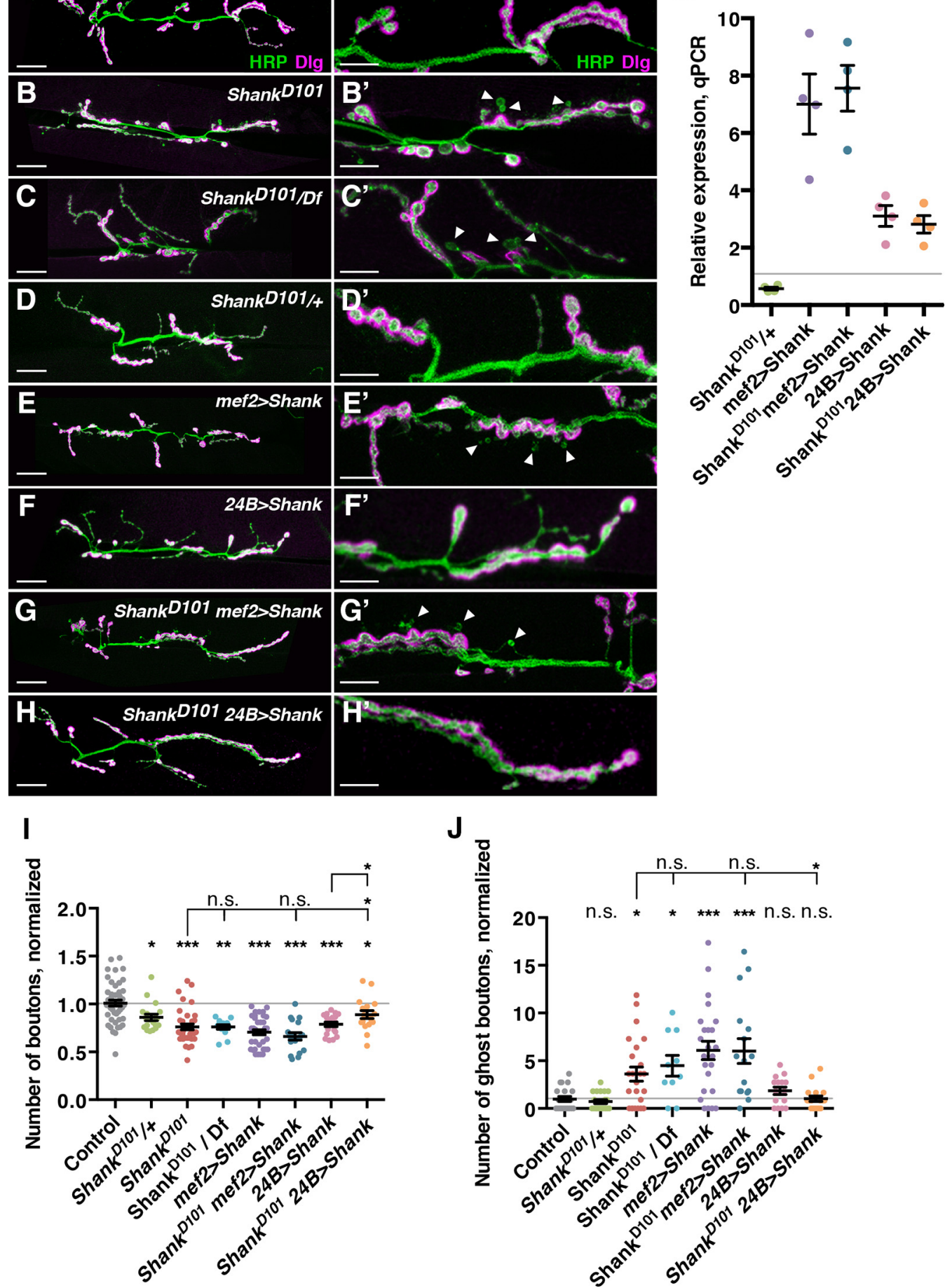

Figure 2. Shank regulates synaptic morphology and maturity in a dose-dependent manner. $\mathbf{A}-\boldsymbol{H}$, Representative NMJs stained with antibodies to Dlg (magenta) and HRP (green). Bouton number is decreased in homozygous Shank null mutants (B), transheterozygotes of the Shank null allele and a chromosomal deficiency (C), Shank heterozygotes (D), and with postsynaptic overexpression of Shank with mef2-GAL4 (E) or 24B-GAL4(F). GBs were identified as round varicosities of HRP staining lacking Dlg staining. GB number is increased in homozygous Shank null mutants ( $\left.\boldsymbol{B}^{\prime}\right)$, Shank/Dftransheterozygotes $\left(\boldsymbol{C}^{\prime}\right)$, and during strong postsynaptic overexpression of Shank with mef2-GAL4 $\left(\boldsymbol{E}^{\prime}\right)$. Restoration of Shank expression in muscle with a moderate $\left(\boldsymbol{H}, \boldsymbol{H}^{\prime}\right)$ but not a strong $\left(\boldsymbol{G}, \boldsymbol{G}^{\prime}\right)$ driver rescued the Shank ${ }^{\text {D101 }}$ phenotypes. Arrowheads indicate GBs. $\boldsymbol{I}, \boldsymbol{J}$, Quantification of total bouton number, normalized to the control average $(\boldsymbol{H})$, and total GB number, normalized to the control average $(\boldsymbol{I})$. Gray line indicates control mean. Data are presented as mean \pm SEM; ${ }^{*} p<0.05,{ }^{* *} p<0.01$, ${ }^{* * *} p<0.001$. n.S., No statistically significant difference. Statistical comparisons are with control unless noted. $\boldsymbol{K}$, Relative expression measured by qPCR. Individual data points represent biological replicates. Shank expression was normalized to the internal reference gene e $1 F-1 A$ and calibrated to control sample. Data are presented as mean $2^{-\Delta \Delta C \tau} \pm$ SEM (see Materials and Methods). Gray line indicates the calibrated control value (=1). Scale bars: $\boldsymbol{A}-\boldsymbol{H}, 20 \mu \mathrm{m} ; \boldsymbol{A}^{\prime}-\boldsymbol{H}^{\prime}, 10 \mu \mathrm{m}$.

We next overexpressed Shank postsynaptically. Surprisingly, Shank overexpression led to phenotypes similar to those observed in Shank loss of function. When Shank expression was driven with the strong muscle driver mef2-GAL4 (mef2>Shank), the animals exhibited a $29 \%$ reduction in the number of boutons per NMJ and a sixfold increase in the average number of GBs per NMJ compared with controls (Fig. 2E, E',I,J; mef2>Shank, $0.71 \pm 0.03$ boutons, $n=37, p<0.0001$, ANOVA; $6.09 \pm 0.96$ 
GBs, $n=24, p<0.0001$, ANOVA). We also expressed Shank with 24B-GAL4, a moderate strength muscle driver (24B>Shank). These animals exhibited a statistically significant $21 \%$ reduction in the number of boutons per NMJ but no significant increase in GBs compared with controls (Fig. 2F, $F^{\prime}, I, J ; 24 B>$ Shank, $0.79 \pm$ 0.05 boutons, $n=19, p=0.0006$, ANOVA; $2.08 \pm 0.46 \mathrm{GBs}, n=$ $19, p>0.9999$, ANOVA).

Morphological defects at the NMJ appeared to vary with the level of Shank expression, with the most severe defects seen in the genotypes Shank ${ }^{D 101}$ and mef2>Shank, in which Shank levels are expected to be the farthest from control levels. To quantify the relative expression of Shank across the genotypes, we analyzed Shank transcripts by qPCR (Fig. $2 K$ ). The qPCR results indicated that the mef2-GAL4 driver produced a large overexpression of Shank $(7.0 \pm 1.05$-fold $)$ and that the $24 B-G A L 4$ driver produced a more moderate overexpression ( $3.1 \pm 0.36$-fold). Shank heterozygotes expressed $\sim 50 \%$ of Shank levels compared with controls $(0.57 \pm 0.05$-fold $)$. No amplification was detected in Shank ${ }^{D 101}$ animals. Given the relationship between morphology and expression level, we hypothesize that Shank function is dose dependent, with optimal levels of Shank required for normal synaptic development.

We next attempted to rescue Shank mutant defects by overexpressing Shank in Shank null mutants. Expression of Shank with mef2-GAL4 (Shank ${ }^{D 101}$ mef2>Shank) failed to rescue the morphology defects compared with Shank ${ }^{D 101}$ mutants (Fig. $2 G, G^{\prime}, I, J$; Shank ${ }^{D 101}$ mef2>Shank, $0.69 \pm 0.04$ boutons, $n=18$, $p=0.8088$, ANOVA; $6.01 \pm 1.67 \mathrm{GBs}, n=16, p=0.3666$, ANOVA). The qPCR analysis confirmed that Shank transcript levels remained extremely high in these animals (7.56 \pm 0.80 fold). Thus, it is not surprising that strong morphological defects persisted in this genotype. In contrast, expression of Shank with 24B-GAL4 in the Shank ${ }^{D 101}$ background (Fig. $2 H, H^{\prime}, I$, J; Shank ${ }^{D 101} 24 B>$ Shank, $0.88 \pm 0.06$ boutons, $n=19 ; 1.64 \pm 0.84$ GBs, $n=17)$ rescued total bouton number $(p=0.0107$, ANOVA) and strongly suppressed GB number $(p=0.0182$, ANOVA) compared with Shank $k^{D 101}$ mutants. Shank ${ }^{D 101}$ $24 B>$ Shank animals also showed a rescue in bouton number compared with the defect seen in 24B-GAL4-overexpressing animals ( $p=0.0378)$. Compared with controls, 24B-GAL4-rescued animals had fewer boutons ( $p=0.0398$, ANOVA) and a normal number of GBs ( $p>0.9999$, ANOVA). Thus, moderate expression of Shank in the Shank ${ }^{D 101}$ background rescued both the reduction in total bouton number and abnormal excess GB formation.

Animals expressing Shank presynaptically at the NMJ (with a neuronal driver; C155>Shank) had no morphological abnormalities compared with controls (C155>Shank, $0.91 \pm$ 0.03 boutons, $n=16, p>0.9999$, ANOVA; $1.22 \pm 0.45 \mathrm{GBs}$, $n=16, p>0.9999$, ANOVA) and no increase in Shank staining intensity at the NMJ (data not shown), consistent with a postsynaptic role for Shank. Furthermore, neuronal expression of Shank in Shank null mutants (Shank ${ }^{D 101}$ C155>Shank) failed to rescue the morphological defects compared with Shank ${ }^{D 101}$ mutants ( $0.65 \pm 0.03$ boutons, $n=12, p=0.9132$, ANOVA; $3.50 \pm 1.12 \mathrm{GBs}, n=12, p>0.9999$, ANOVA). Thus, our data support the hypothesis that an optimal postsynaptic Shank concentration is required to support normal synaptic development, and Shank dosage affects both the number and maturity of synaptic boutons.

\section{Glutamate receptors and AZs are not affected in Shank mutants}

We next tested whether the organization of neurotransmitter release sites was affected in Shank mutants by staining for Brp, a marker of the presynaptic AZ, and GluRIII, an obligate subunit of the postsynaptic glutamate receptor (Fig. $3 A, B$ ). In Shank mutants, AZ density was not significantly different from controls (Fig. 3I; control, $0.3483 \pm 0.02 \mathrm{AZs}$ per volume, $n=16$; Shank ${ }^{D 101}, 0.33 \pm 0.01$ AZs per volume, $n=18, p=0.3706$, Student's $t$ test). Furthermore, GluRIII clusters were not significantly different with respect to size (Fig. $3 G$ : control, $1.55 \pm 0.08$ $\mu \mathrm{m}^{3}$ per GluR, $n=110$; Shank ${ }^{D 101}, 1.68 \pm 0.09 \mu \mathrm{m}^{3}$ per GluR, $n=86, p=0.2487$, Student's $t$ test), or fluorescence intensity (Fig. $3 H$; control, $0.86 \pm 0.05$ GluR per HRP fluorescence, $n=$ 26; Shank ${ }^{D 101}, 0.78 \pm 0.04$ GluR per HRP fluorescence, $n=26$, $p=0.1856$, Student's $t$ test). The apposition of Brp and GluRIII was also unaffected (Fig. $3 A, B$ ).

Glutamate receptors exist in two possible four-subunit configurations, containing either subunit IIA or IIB, along with three obligate subunits (IIC/III, IID, and IIE). IIA- and IIB-containing receptors differ in their functional properties (DiAntonio et al., 1999), and the incorporation of IIA versus IIB changes as the PSD matures (Schmid et al., 2008). We examined GluRIIA (Fig. 3C,D) and GluRIIB (Fig. 3E,F) in Shank ${ }^{D 101}$ mutants. We stained for GluRIIA and measured no statistically significant differences between Shank ${ }^{D 101}$ and control animals with respect to size (Fig. 3G: control, $1.72 \pm$ $0.08 \mu \mathrm{m}^{3}$ per GluR, $n=133$; Shank ${ }^{D 101}, 1.52 \pm 0.06 \mu \mathrm{m}^{3}$ per GluR, $n=124, p=0.0521$, Student's $t$ test) or fluorescence intensity (Fig. $3 \mathrm{H}$ : control, $0.34 \pm 0.05$ GluR per HRP fluorescence, $n=9$; Shank ${ }^{D 101}, 0.30 \pm 0.05$ GluR per HRP fluorescence, $n=10, p=0.5507$, Student's $t$ test) of GluRIIA clusters. We then assayed GluRIIB by expressing a GFP-labeled GluRIIB using its endogenous promoter (Schmid et al., 2008) in control and Shank mutant backgrounds. Similar to what we observed for GluRIIA and GluRIII, Shank ${ }^{D 101}$ mutants resembled controls with respect to the size (Fig. $3 G$ : control, $1.75 \pm$ $0.10 \mu \mathrm{m}^{3}$ per GluR, $n=129$; Shank ${ }^{D 101}, 1.56 \pm 0.07 \mu \mathrm{m}^{3}$ per GluR, $n=119, p=0.1290$, Student's $t$ test) and fluorescence intensity (Fig. $3 \mathrm{H}$ : control, $0.29 \pm 0.03$ GluR per HRP fluorescence, $n=11$; Shank ${ }^{D 101}, 0.24 \pm 0.01$ GluR per HRP fluorescence, $n=10, p=0.1213$, Student's $t$ test) of GluRIIB clusters. Thus, Shank ${ }^{D 101}$ animals did not exhibit defects in the organization of individual release sites. However, given a normal density of AZs per bouton (Fig. 3I) and a decrease in the number of boutons per NMJ (Fig. 2), Shank mutants had an overall reduction in the number of neurotransmitter release sites per NMJ compared with controls.

\section{Shank regulates synaptic ultrastructure}

We next examined the synaptic ultrastructure of Shank mutant animals using electron microscopy (Fig. 3J,K). Shank mutants had normal presynaptic ultrastructure (Fig. $3 K$, red arrowhead) but exhibited defects in the SSR, a system of membranous infoldings that comprise the postsynaptic membrane at the NMJ. Because GBs lack SSR completely (Packard et al., 2002; Ataman et al., 2006), we measured boutons surrounded by SSR to assess the ultrastructure of more mature terminals. Loss of Shank resulted in a less complex SSR compared with controls, with fewer membranous folds (Fig. $3 L$; control, $0.69 \pm 0.02$ area of infoldings per SSR area, $n=29$; Shank ${ }^{D 101}$, $0.56 \pm 0.02, n=22, p<0.0001$, Student's $t$ test). Mutants also had numerous regions of the presynaptic terminal that did not 

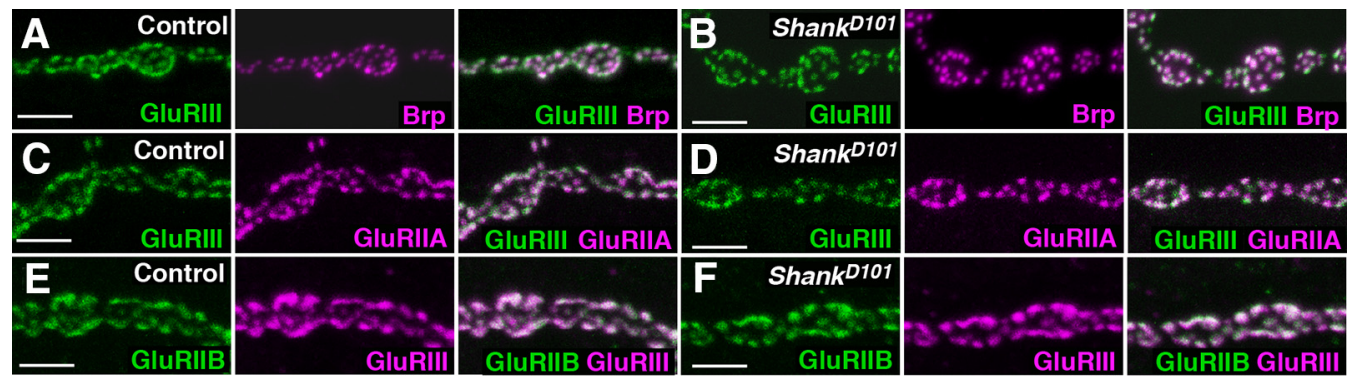

G
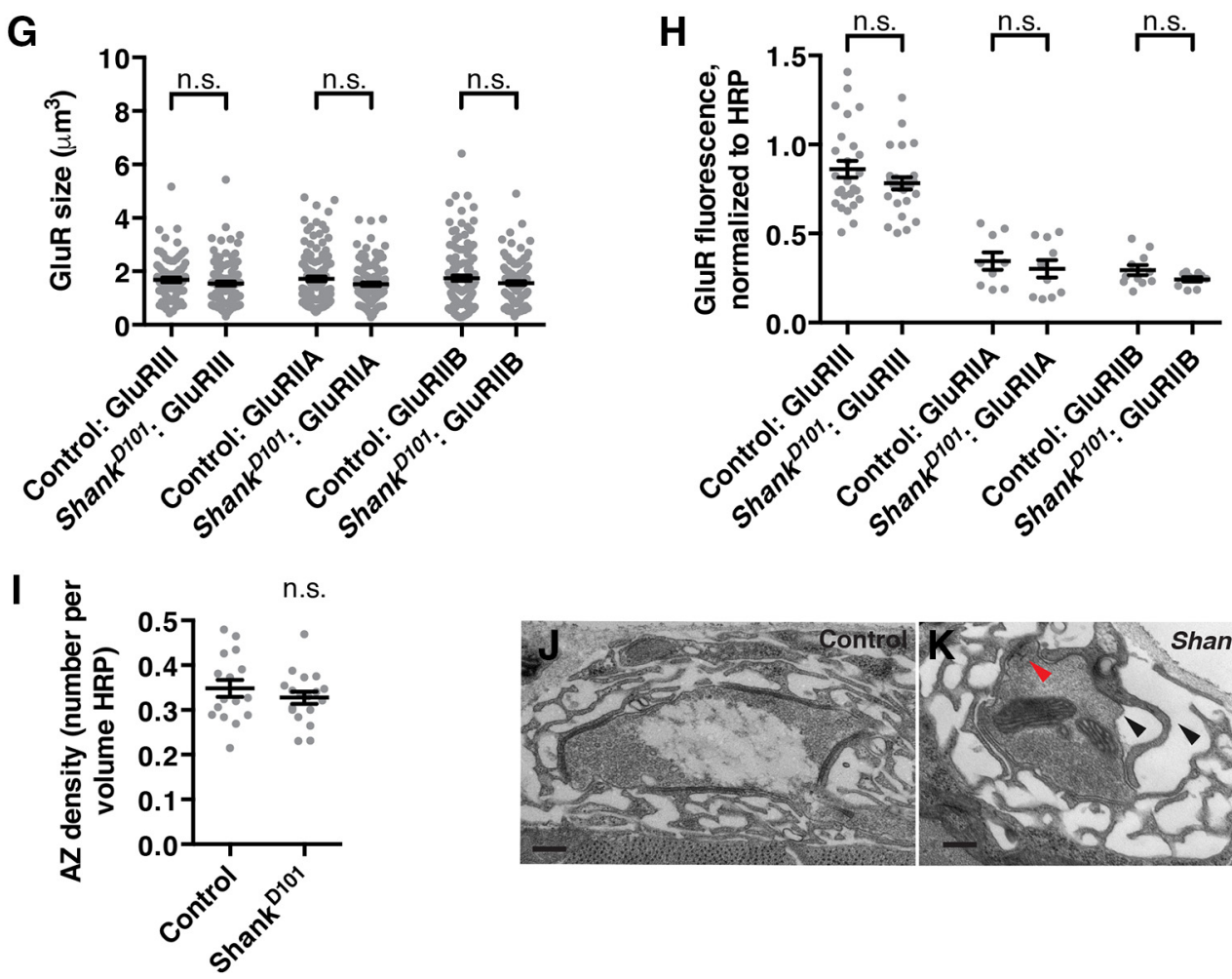

$\mathbf{L}$

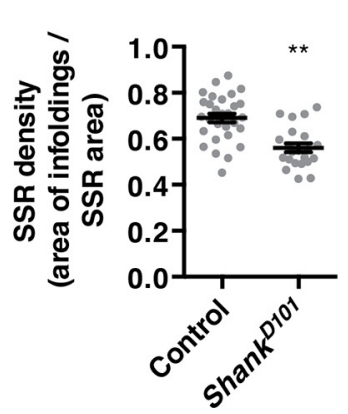

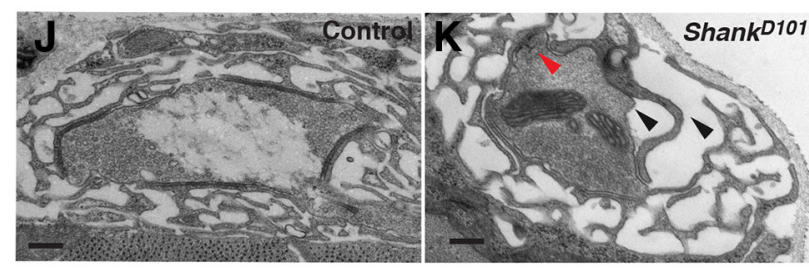

M

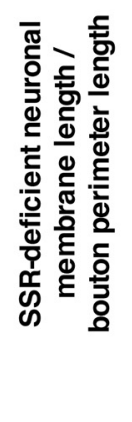

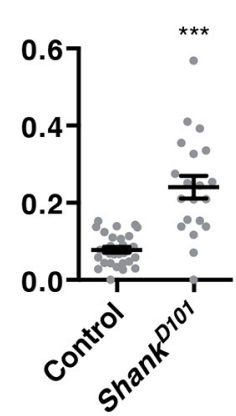

N

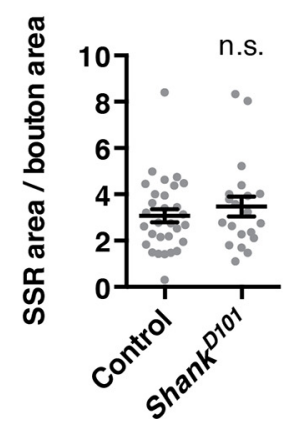

Figure 3. Shank regulates SSR ultrastructure but not AZ organization. $\boldsymbol{A}, \boldsymbol{B}$, Representative NMJs stained with antibodies to GluRIII (green) and Brp (magenta). C, D, Representative NMJs stained with antibodies to GluRIII (green) and GluRIIA (magenta). $\boldsymbol{E}$, F, Representative NMJs stained with antibodies to GluRIIB (green) and GluRIII (magenta). Glutamate receptor clusters and AZs appear normal in Shank null mutants. $\mathbf{G}-\boldsymbol{I}$, Quantification of GluR size $(\boldsymbol{G})$, GluR fluorescence $(\boldsymbol{H})$, and AZ density $(\boldsymbol{I})$. $\boldsymbol{J}, \boldsymbol{K}$, Transmission electron microscopy of a bouton and surrounding SSR in control $(\boldsymbol{J})$ and Shank ${ }^{D 101}(\boldsymbol{K})$. Homozygous Shank mutants have reduced SSR density and gaps between the neuronal membrane and SSR (black arrowheads). T-bar structure appears normal (red arrowhead). $\mathbf{L}-\boldsymbol{N}$, Quantification of SSR density, calculated as the area of SSR infoldings normalized to SSR cross-sectional area ( $L$ ), SSR-deficient neuronal membrane, calculated as the length of neuronal membrane without adjacent SSR membrane normalized to the total bouton perimeter $(\boldsymbol{M})$, and cross-sectional SSR area, normalized to bouton area $(\boldsymbol{N})$. Data are presented as mean \pm SEM; ${ }^{* *} p<$ $0.01,{ }^{* * *} p<0.001$. n.s., Not significant. Scale bars: $A-F, 5 \mu \mathrm{m} ; J, K, 200 \mathrm{~nm}$.

contact the SSR compared with controls in which these surfaces are typically in close contact (Fig. $3 M$; control, $0.08 \pm$ 0.01 SSR-deficient membrane length per bouton perimeter length, $n=30$; Shank ${ }^{D 101}, 0.24 \pm 0.03, n=20, p<0.0001$, Student's $t$ test). The overall area of the SSR was unchanged in mutants compared with controls (Fig. $3 \mathrm{~N}$; control, $3.08 \pm 0.29$
SSR area per bouton area, $n=30$; Shank $k^{D 101}, 3.48 \pm 0.43, n=$ $20, p=0.4260$, Student's $t$ test). These findings suggest that, in addition to an increase in immature GBs lacking postsynaptic specializations, Shank ${ }^{D 101}$ animals also have postsynaptic defects at mature boutons, in which the SSR has fewer infoldings and makes less contact with the neuronal membrane. 


\section{Shank regulates the postsynaptic FNI pathway}

Postsynaptic defects, including excess GB formation and abnormal development of the SSR, have been linked to impairment of the noncanonical Wnt FNI pathway (Packard et al., 2002; Ataman et al., 2006; Mosca and Schwarz, 2010; Speese et al., 2012). Because Shank mutants exhibit similar defects, we tested whether FNI is affected by perturbation of Shank. One readily observable step in the FNI pathway is nuclear import of Fz2-C (Mathew et al., 2005), which occurs after activation of the Fz2 receptor by its ligand Wg. We examined Fz2-C localization by staining with an antibody against the Fz2 C terminus (Mathew et al., 2005). Control animals accumulated Fz2-C puncta in their muscle nuclei as described previously (Mathew et al., 2005; Fig. 4A, E; $2.24 \pm 0.37$ puncta per nucleus, $n=38$ ). However, the number of nuclear puncta was significantly decreased in both Shank ${ }^{D 101}$ (Fig. 4B,E; $0.30 \pm 0.10$ puncta per nucleus, $n=30, p<0.0001$, ANOVA) and mef $2>\operatorname{Shank}$ (Fig. $4 C, E ; 0.35 \pm 0.14$ puncta per nucleus, $n=$ 23, $p=0.0002$, ANOVA) compared with controls. This finding indicates that FNI is impaired after both loss and overexpression of Shank. Fz2-C was restored in animals expressing Shank with $24 B-G A L 4$ in the Shank ${ }^{D 101}$ background (Fig. $4 D, E ; 1.46 \pm 0.40$ puncta per nucleus, $n=23$ ) compared with both null mutant animals $(p=0.0359$, ANOVA $)$ and mef2 $>$ Shank animals ( $p=0.0421$, ANOVA), consistent with the hypothesis that Fz2-C nuclear import is regulated by Shank and sensitive to Shank expression.

We next tested whether Shank mutant defects could be rescued by expressing an Fz2-C fragment with a nuclear localization signal (NLS; Mathew et al., 2005). Expression of this transgene drives Fz2-C into the nucleus, bypassing the FNI pathway, and rescues postsynaptic defects in FNI pathway mutants (Mosca and Schwarz, 2010). Indeed, expression of $m y c-N L S-F z 2-C$ with mef2-GAL4 strongly suppressed the increase in GBs associated with loss of Shank function (Fig. $4 F^{\prime}, G^{\prime}, H^{\prime}, J$; control, $1.00 \pm 0.04$ GBs, $n=16$; Shank ${ }^{D 101}$, $4.78 \pm 1.35$ GBs, $n=15$; Shank ${ }^{D 101}$ mef2 $>$ Fz2C.nls, $1.34 \pm 0.42 \mathrm{GBs}, n=22$ ), resulting in a significant rescue compared with Shank mutant animals $(p=0.0027$, ANOVA). Expression of a control transgene (mef2>GFP-NLS) had no effect (Fig. $4 I^{\prime}$,J; $3.34 \pm 0.85$ GBs, $n=20, p=0.4710$, ANOVA). These findings support the hypothesis that impairment of FNI underlies the excess GB formation observed in Shank $k^{D 101}$. In contrast, expressing $m y c-N L S-F z 2-C$ in the Shank ${ }^{D 101}$ background did not produce a complete rescue of bouton number compared with Shank mutants (Fig. 4G, H, K; Shank $k^{D 101}, 0.71 \pm 0.03$ boutons, $n=15$; Shank ${ }^{D 101}$ mef2>Fz2C.nls, $0.82 \pm 0.04$ boutons, $n=22, p=0.0819$, ANOVA), nor did expression of GFP-NLS (Fig. 4I, K; $0.70 \pm 0.03$ boutons, $n=20, p=0.9766$, ANOVA). Thus, the size of the synaptic arbor is likely regulated through additional functions of Shank at the NMJ.

Wnt signaling at the NMJ is bidirectional, with a presynaptic canonical pathway that is separable from the postsynaptic FNI pathway. Mutations of the presynaptic Wnt pathway affect bouton number, size, and presynaptic microtubule organization (Packard et al., 2002; Ataman et al., 2006; Miech et al., 2008). We did not detect any defect in bouton size in Shank ${ }^{D 101}$ animals (Fig. $4 L$; control, $3.77 \pm 0.14 \mu \mathrm{m}, n=8$; Shank ${ }^{D 101}, 3.69 \pm 0.18 \mu \mathrm{m}$, $n=8, p=0.7466$, Student's $t$ test). We also did not detect any defects in microtubule organization, determined by staining for the microtubule-associated protein Futsch (Fig. 4M-O; control, $0.25 \pm 0.04 \%$ boutons with Futsch loops, $n=8$; Shank ${ }^{D 101}$, $0.28 \pm 0.03 \%$ boutons with Futsch loops, $n=8, p=0.4084$,
Student's $t$ test). These findings indicate that the presynaptic Wnt pathway is not affected during perturbation of Shank.

\section{Shank regulates internalization of $\mathrm{Fz} 2$}

To investigate how Shank might interact with the FNI pathway, we tested for colocalization between Shank and the Fz2 receptor. Examining colocalization of endogenous proteins was not feasible, because the available antisera are all produced in rabbits. Therefore, we took two independent approaches: first expressing Shank-GFP (mef2>Shank-GFP) and immunostaining for Fz2 using an antibody against the $\mathrm{C}$ terminus (Mathew et al., 2005), and second expressing Fz2-GFP (mef2>Fz2-GFP; Chen et al., 2004) and immunostaining for Shank. In both cases, we observed colocalization between Shank and Fz2 at the postsynaptic membrane; both proteins surround the bouton, with the Shank domain extending outside of the Fz2 domain and with a region of overlap between them (Fig. 5A,B). Shank-GFP, Fz2-GFP, and anti-Fz2 are also found in a punctate pattern in the muscle cytoplasm, but we detected no colocalization between Shank and Fz2 on these populations of puncta.

We reasoned that one mechanism by which Shank might regulate Fz2-C nuclear localization is by affecting the internalization of Fz2 at the plasma membrane. To test this model, we measured surface and internalized Fz2 receptors over time with an antibody internalization assay (Mathew et al., 2005; Ataman et al., 2006). Surface levels of Fz2 were the same among control, Shank ${ }^{D 101}$, and mef $2>$ Shank animals, indicating normal trafficking of the receptor to the postsynaptic membrane (Fig. 5C-E,G: control, $0.19 \pm 0.02$ surface Fz2-N, $n=8$; Shank ${ }^{D 101}, 0.17 \pm 0.01$ surface Fz2-N, $n=8$; mef2 $>$ Shank, $0.22 \pm 0.03$ surface Fz2-N, $n=8$; $p$ (control vs Shank $\left.{ }^{D 101}\right)=0.7224$, ANOVA; $p$ (control vs mef $2>$ Shank $)=0.6309$, ANOVA). However, we detected a significant decrease in Shank ${ }^{D 101}$ in the pool of internalized Fz2 (Fig. $5 C, D, F$ : control, $1.42 \pm 0.08$ internalized Fz2-N, $n=8$; Shank ${ }^{D 101}, 1.03 \pm 0.012$ internalized Fz2-N, $n=8, p=0.0283$, ANOVA). This evidence suggests that reduced internalization of the Fz2 receptor is one mechanism by which the FNI pathway is downregulated in Shank ${ }^{D 101}$ animals. To test whether the total level of Fz2 protein is affected by Shank, we performed Western blots on larval body wall extracts from control or Shank ${ }^{D 101}$ animals expressing Fz2-GFP postsynaptically (Fig. $5 \mathrm{H}$ ). The level of Fz2-GFP detected by Western blot was not altered in Shank ${ }^{D 101}$ mutant animals (mef2>Fz2-GFP, $1.43 \pm 0.15$ GFP signal per tubulin signal, $n=4$; Shank ${ }^{D 101}$ mef2 $>$ Fz2-GFP, $1.44 \pm 0.14$ GFP signal per tubulin signal, $n=5$ ), indicating that the Fz2 internalization defect measured at the synapse is not attributable to an indirect role of Shank in the production or degradation of Fz2 protein.

Notably, mef2 $>$ Shank animals exhibited normal levels of internalized Fz2 (Fig. 5E, F: mef2>Shank, $1.27 \pm 0.10$ internalized Fz2-N, $n=8, p=0.4883$, ANOVA). Thus, downregulation of the FNI pathway during overexpression of Shank may occur through a distinct mechanism. Because mef $2>$ Shank animals lose nuclear accumulation of Fz2-C, the defect must occur between internalization of the Fz2 receptor and its transport/import into the nucleus. As such, Shank likely acts to organize regulators at the postsynaptic membrane that both internalize the Fz2 receptor and mediate its trafficking to the nucleus.

\section{Discussion}

By generating Drosophila mutants completely lacking any Shank protein, we identified a novel function of this synaptic scaffolding protein in synapse development. We found that aberrant expres- 

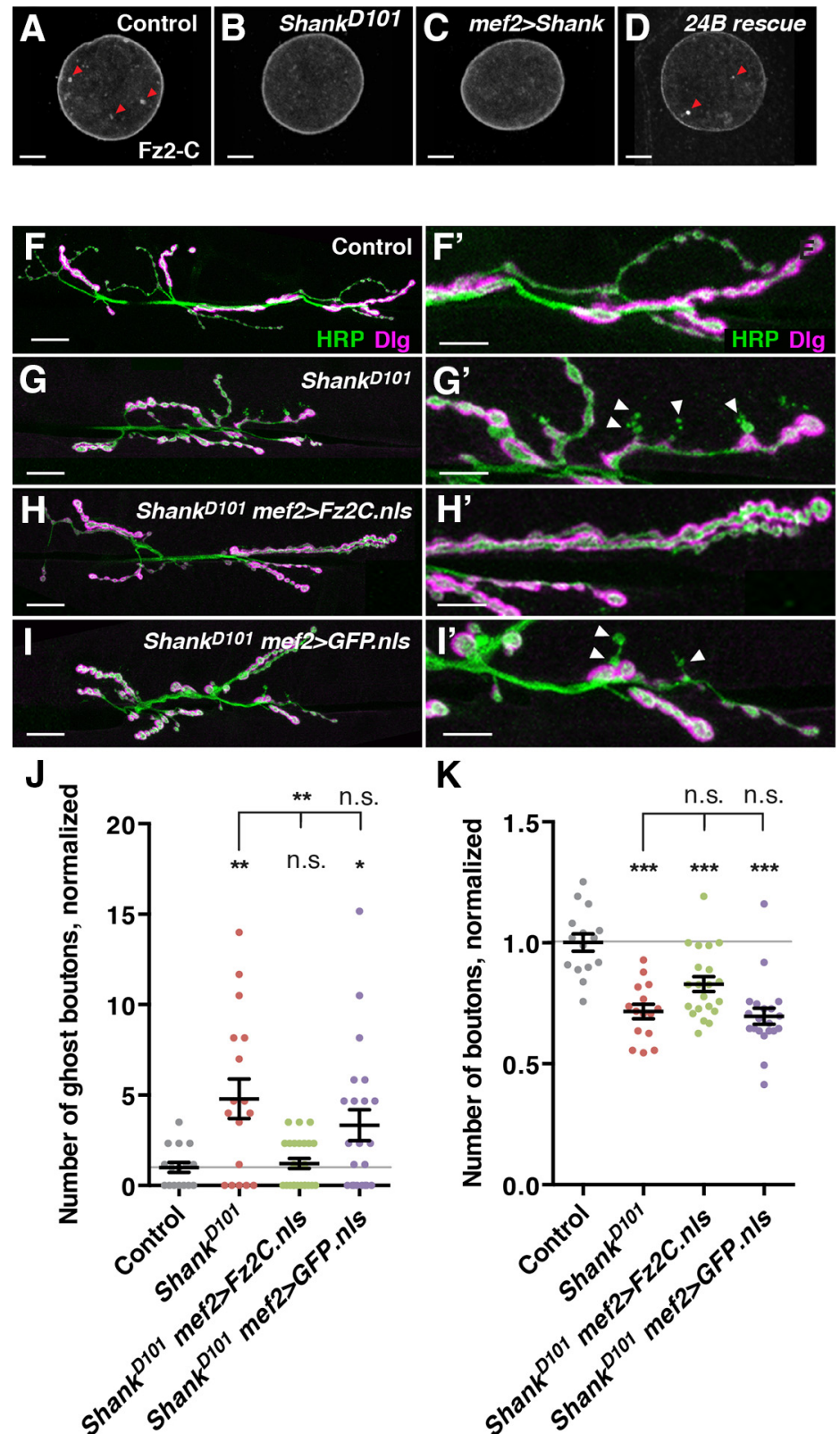

K
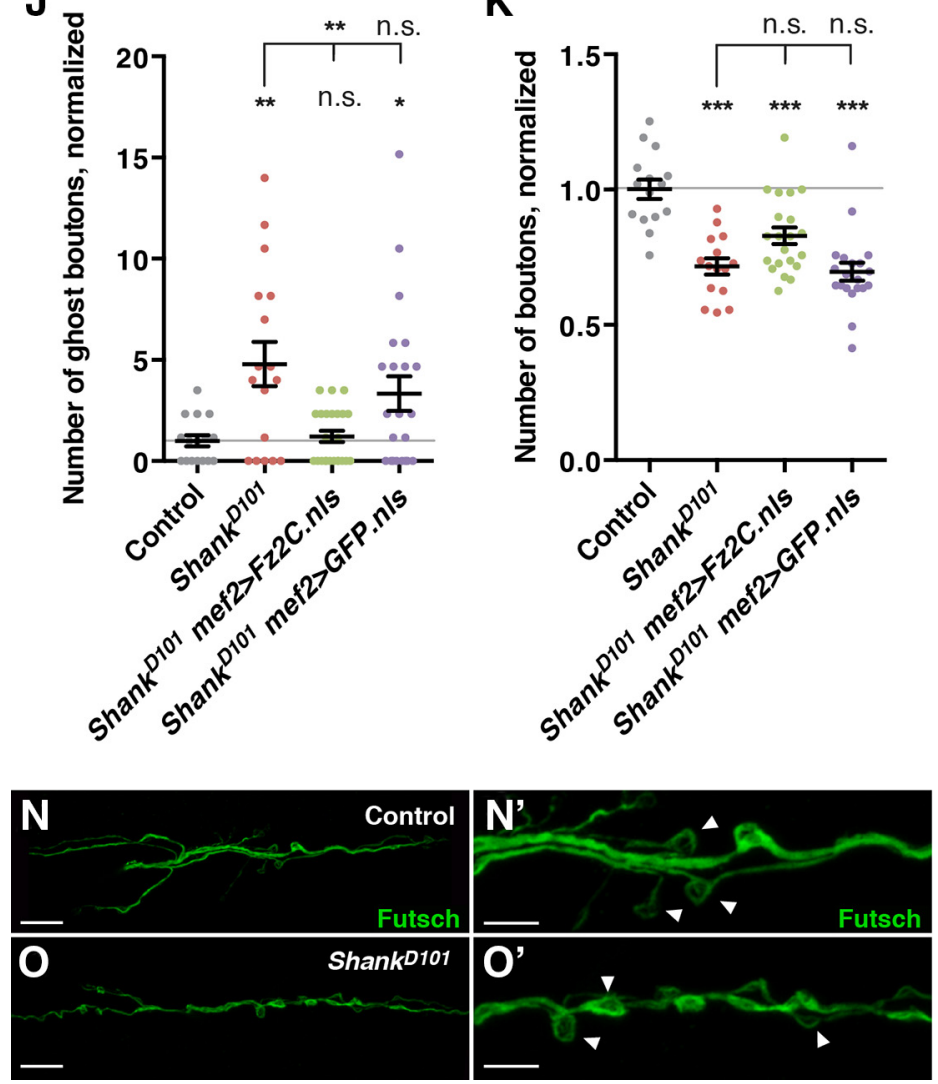

$\mathbf{L}$
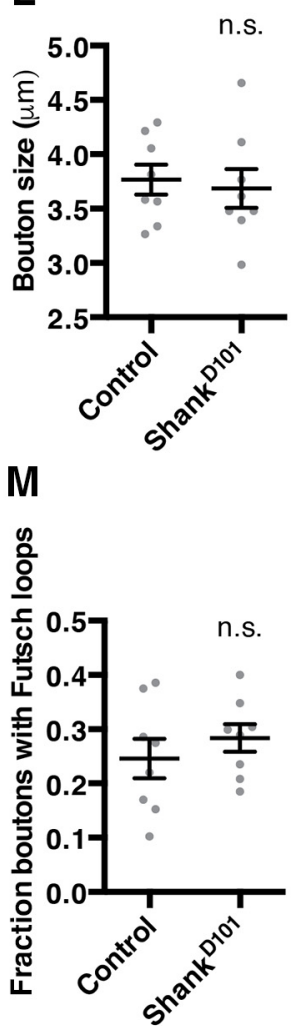

Figure 4. Shank regulates the postsynaptic FNI pathway. $A-D$, Representative muscle nuclei stained with antibodies to the $C$ terminus of Fz2. The number of Fzz-C puncta (red arrowheads) is reduced with homozygous loss of Shank (B) or postsynaptic overexpression of Shank (C). The Shank ${ }^{D 101}$ mutant defect is rescued by postsynaptic overexpression of Shank with $24 B-G A L 4$ (D). $\boldsymbol{E}$, Quantification of Fz2-C puncta per nucleus. $\boldsymbol{F}-\boldsymbol{I}$, Representative NMJs stained with antibodies to Dlg (magenta) and HRP (green). Expression of Fz2-C.n/s gives a strong rescue of the Shank GB phenotype $\left(\boldsymbol{H}, \boldsymbol{H}^{\prime}\right)$. Expression of GFP.n/s has no rescue effect $\left(\boldsymbol{I}, \boldsymbol{I}^{\prime}\right)$. Arrowheads indicate GBs. $\boldsymbol{J}, \boldsymbol{K}$, Quantification of GB number, normalized to the control average $(\boldsymbol{J})$, and total bouton number, normalized to the control average $(\boldsymbol{K})$. Gray line indicates control mean. $\boldsymbol{L}$, Quantification of bouton size. $\boldsymbol{M}$, Quantification of Futsch loops. $\boldsymbol{N}-\mathbf{0}$, Representative NMJs stained with Futsch to visualize microtubules. Arrowheads indicate Futsch loops. Data are presented as mean $\pm \mathrm{SEM} ;{ }^{*} p<0.05,{ }^{* *} p<0.01,{ }^{* * *} p<0.001$. n.s., Not significant. Statistical comparisons are with control unless noted. Scale bars: $A-D, 5 \mu \mathrm{m} ; \boldsymbol{F}-\mathbf{I}, \mathbf{N}, \mathbf{0}, 20 \mu \mathrm{m} ; \boldsymbol{F}^{\prime}-\boldsymbol{I}^{\prime}, \boldsymbol{N}^{\prime}, \mathbf{O}^{\prime}, 10 \mu \mathrm{m}$.

sion of Shank results in defects affecting synapse number, maturity, and ultrastructure, and that a subset of these defects is attributable to a downregulation of a noncanonical Wnt signaling pathway in the postsynaptic cell (Fig. 6).
Shank mutant phenotypes from flies to mammals

The defects we observed in Shank mutants are mostly consistent with defects described from in vivo and in vitro rodent models of Shank. Synaptic phenotypes reported from Shank mutants vary, 

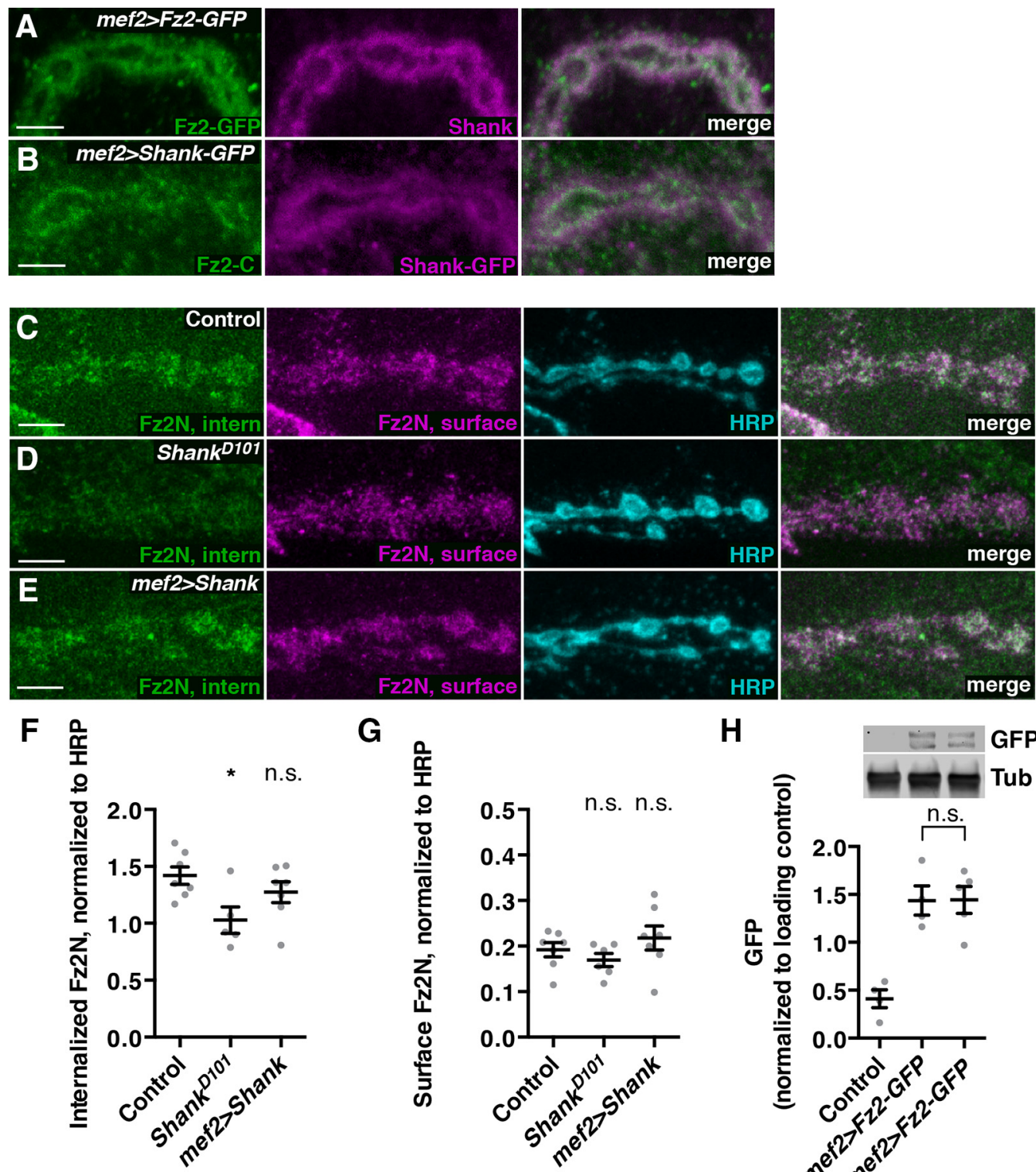

H

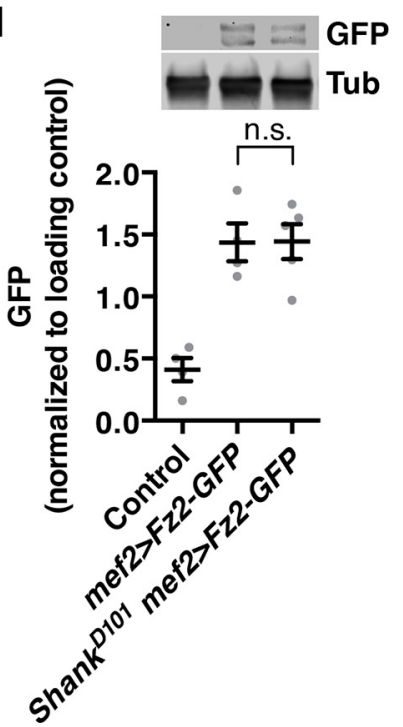

Figure 5. Shank regulates internalization of Fz2. A, Representative NMJ from an animal expressing FZ2-GFP (green) stained with antibodies to Shank (magenta). $\boldsymbol{B}$, Representative NMJ from an animal expressing Shank-GFP (magenta) stained with antibodies to Fz2-C (green). C-E, Representative NMJs stained to label the internalized pool (green) and surface pool (magenta) of Fz2, with an antibody against an extracellular epitope in the $\mathrm{N}$ terminus. Shan ${ }^{D 101}$ animals exhibited a reduction in the internalized pool of Fz2 (D). F, G, Quantification of internalized Fz2, normalized to HRP signal $(\boldsymbol{F})$, and surface Fz2, normalized to HRP signal $(\boldsymbol{G})$. $\boldsymbol{H}$, Western blot and quantification of body wall muscle extracts from control animals (the UAS-Fz2-GFP line with no driver), animals expressing Fz2-GFP (mef2>FZ2-GFP), and Shank ${ }^{\text {D101 }}$ animals expressing Fz2-GFP (Shank ${ }^{D 101}$ mef2>FZ2-GFP), probed for GFP and tubulin (Tub; loading control). The level of expression of FZ2-GFP is not affected in the Shank ${ }^{101}$ mutant background. Data are presented as mean \pm SEM; ${ }^{*} p<0.05$. n.s., Not significant. Statistical comparisons are with control unless noted. Scale bars: $A, B, 5 \mu \mathrm{m} ; C-E, 10 \mu \mathrm{m}$.

likely reflecting incomplete knockdown of Shank splice variants, and heterogeneity in the requirement for Shank between the different brain regions and developmental stages analyzed (for review, see Jiang and Ehlers, 2013). Nevertheless, taken collectively, analyses of Shank1-Shank3 mutant mice indicate that Shank genes regulate multiple parameters of the structure and function of glutamatergic synapses, including the morphology of dendritic spines and the organization of proteins in the PSD (Hung et al., 2008; Bozdagi et al., 2010; Peça et al., 2011; Wang et al., 2011; Schmeisser et al., 2012; Won et al., 2012; Kouser et al., 2013; Speed et al., 2015).
By removing all Shank protein in Drosophila, we identified essential functions for Shank at a model glutamatergic synapse. Shank mutants exhibit prominent abnormalities in synaptic structure, including a decrease in the total number of synaptic boutons, which results in an overall decrease in the number of AZs. In addition, a subset of synaptic boutons fails to assemble a postsynaptic apparatus. Finally, even in mature boutons, the SSR has fewer membranous folds and makes less frequent contact with the presynaptic membrane, indicating a defect in postsynaptic development. The SSR houses and concentrates important synaptic components near the synaptic cleft, including scaffold- 
A

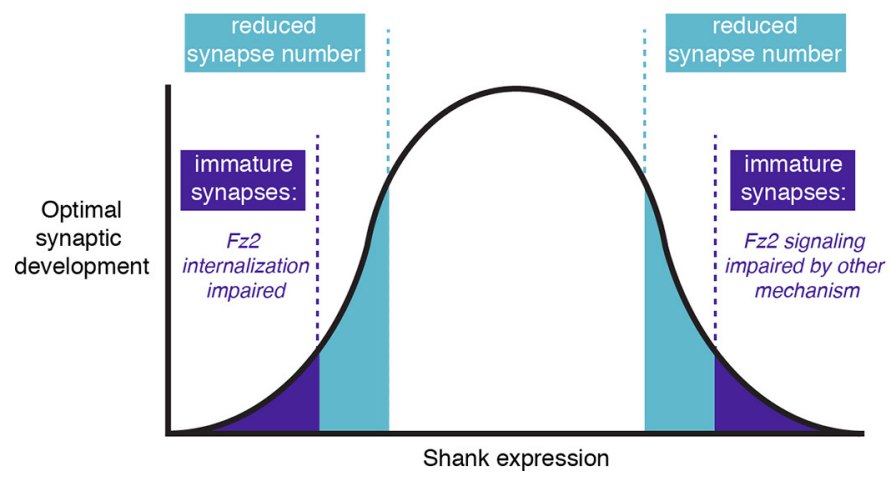

B

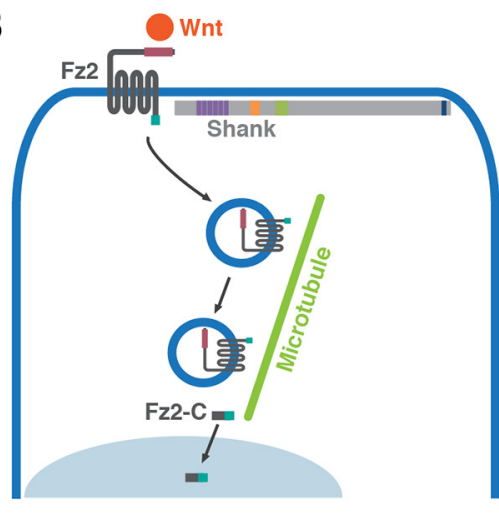

Figure 6. Model of Shank function. $\boldsymbol{A}$, Shank functions in a dose-dependent manner to regulate multiple parameters of synapse biology. Both partial loss and partial overexpression of Shank (blue) result in a reduction in the number of synapses at the NMJ. Very low and very high levels of Shank (purple) produce both synapse number defects and synapse maturation defects. The synapse maturation defects are associated with downregulation of FNI signaling. In Shank mutants, the mechanism of FNI downregulation is an impairment of Fz2 internalization from the membrane, whereas for high Shank overexpression, FNI impairment occurs by a different mechanism. B, Shank localizes to the postsynaptic membrane in which it regulates internalization of the Wnt receptor $\mathrm{Fz2}$ to regulate synapse maturation. In the FNI signaling pathway, Fz2 is subsequently transported on microtubules and cleaved, and Fz2-C is imported into the nucleus to regulate synaptic transcription.

ing proteins, adhesion molecules, and glutamate receptors. Thus, defects in SSR development can affect the assembly and regulation of synaptic signaling platforms. Our findings indicate that Shank is a key regulator of synaptic growth and maturation.

\section{Gene dosage of Shank}

Our findings also indicate that gene dosage of Shank is critical for normal synapse development at Drosophila glutamatergic NMJs. The morphological phenotypes we observe scale with the level of Shank expression, with mild phenotypes seen with both $50 \%$ loss and moderate overexpression of Shank, and severe phenotypes seen with both full loss and strong overexpression of Shank (Fig. 6). The observation of synapse loss in heterozygotes of the Shank null allele is significant, because haploinsufficiency of SHANK3 is well established as a monogenic cause of ASD (Betancur and Buxbaum, 2013).

Consistent with the observation that excess Shank is detrimental, duplications of the SHANK3 genomic region (22q13) are known to cause a spectrum of neuropsychiatric disorders. Large duplications spanning SHANK3 and multiple neighboring genes have been reported in individuals with attention deficit-hyperactivity disorder (ADHD), schizophrenia, and ASD (Durand et al., 2007; Failla et al., 2007; Moessner et al., 2007). Smaller duplications, spanning SHANK3 and only one or two adjacent genes, have been reported in individuals with ADHD, epilepsy, and bipolar disorder (Han et al., 2013). Furthermore, duplication of the Shank3 locus in mice results in manic-like behavior, seizures, and defects in neuronal excitatory/inhibitory balance (Han et al., 2013). Thus, the requirement for proper Shank dosage for normal synaptic function may be a conserved feature.

\section{Shank as a regulator of synapse-to-nucleus Wnt signaling}

One unexpected finding from our study was the identification of a previously unappreciated aspect of Shank as a regulator of Wnt signaling. Shank regulates the internalization of the transmembrane Fz2 receptor, thus affecting transduction of Wnt signaling from the plasma membrane to the nucleus. Downregulation of this pathway is implicated in impaired postsynaptic organization, including supernumerary GBs and SSR defects (Ataman et al., 2006; Mosca and Schwarz, 2010). The physical proximity of Shank and Fz2 at the postsynaptic membrane suggests that Shank directly or indirectly modulates the internalization of Fz2. Shank is a scaffolding protein with many binding partners that could contribute to such an interaction (Jiang and Ehlers, 2013). One intriguing possibility is the PDZ-containing protein Grip. Shank2 and Shank3 have been reported to bind Grip1 (Sheng and Kim, 2000; Uemura et al., 2004). Furthermore, Drosophila Grip transports Fz2 to the nucleus on microtubules to facilitate the FNI pathway (Ataman et al., 2006). Thus, an interaction between Shank, Fz2, and Grip to regulate synaptic signaling is an attractive model.

Although loss of Shank is associated with impaired internalization of the Fz2 receptor, how excess Shank leads to FNI impairment remains an open question. One possibility is that an increase in the concentration of the Shank scaffold at the synapse physically impedes the transport of Fz2 or other components of the pathway or saturates binding partners that are essential for Fz2 trafficking. Both overexpression and loss of function of Shank ultimately lead to a failure to accumulate the cleaved Fz2 C terminus within the nucleus, in which it is required to interact with RNA binding proteins that facilitate transport of synaptic transcripts to postsynaptic compartments. Although Shank and Wnt both play important synaptic roles, this study is the first demonstration of a functional interaction between Shank and Wnt signaling at the synapse.

\section{Shank as a regulator of glutamate receptors}

Intriguingly, we find no obvious defects in glutamate receptor levels or distribution in the absence of Shank. This was surprising given the role for Shank in regulating the FNI pathway, and downregulation of FNI was shown previously to lead to increased GluR field size (Speese et al., 2012). Several studies have reported changes in the levels of AMPA or NMDA receptor subunits in Shank mutant mice (Bozdagi et al., 2010; Peça et al., 2011; Wang et al., 2011; Verpelli et al., 2012), although others have also observed no changes (Verpelli et al., 2011; Kouser et al., 2013; Speed et al., 2015). Levels of metabotropic glutamate receptors are also affected in some Shank mutant models (Verpelli et al., 2011; Kouser et al., 2013). Moreover, transfected Shank3 can recruit functional glutamate receptors in cultured cerebellar neurons (Roussignol et al., 2005). It is possible that Drosophila Shank mutants have defects in GluRs that are too subtle to detect with our current methodology. Another possibility is that Shank is involved in signaling mechanisms that are secondary to FNI and 
that lead to compensatory changes in GluRs at individual synapses. Indeed, our results are consistent with Shank having additional functions at the synapse in addition to its role in FNI, particularly affecting synaptic bouton number. In conclusion, we find that the sole Drosophila Shank homolog functions to regulate synaptic development in a dose-dependent manner, providing a new model system to further investigate how loss of this scaffolding protein may underlie neurodevelopmental disease.

\section{References}

Andersen CL, Jensen JL, Ørntoft TF (2004) Normalization of real-time quantitative reverse transcription-PCR data: a model-based variance estimation approach to identify genes suited for normalization, applied to bladder and colon cancer data sets. Cancer Res 64:5245-5250. CrossRef Medline

Ataman B, Ashley J, Gorczyca D, Gorczyca M, Mathew D, Wichmann C, Sigrist SJ, Budnik V (2006) Nuclear trafficking of Drosophila Frizzled-2 during synapse development requires the PDZ protein dGRIP. Proc Natl Acad Sci U S A 103:7841-7846. CrossRef Medline

Ataman B, Ashley J, Gorczyca M, Ramachandran P, Fouquet W, Sigrist SJ, Budnik V (2008) Rapid activity-dependent modifications in synaptic structure and function require bidirectional Wnt signaling. Neuron 57: 705-718. CrossRef Medline

Bellen HJ, Levis RW, He Y, Carlson JW, Evans-Holm M, Bae E, Kim J, Metaxakis A, Savakis C, Schulze KL, Hoskins RA, Spradling AC (2011) The Drosophila gene disruption project: progress using transposons with distinctive site specificities. Genetics 188:731-743. CrossRef Medline

Betancur C, Buxbaum JD (2013) SHANK3 haploinsufficiency: a "common" but underdiagnosed highly penetrant monogenic cause of autism spectrum disorders. Mol Autism 4:17. CrossRef Medline

Blunk AD, Akbergenova Y, Cho RW, Lee J, Walldorf U, Xu K, Zhong G, Zhuang X, Littleton JT (2014) Postsynaptic actin regulates active zone spacing and glutamate receptor apposition at the Drosophila neuromuscular junction. Mol Cell Neurosci 61:241-254. CrossRef Medline

Boyd JB, Golino MD, Shaw KE, Osgood CJ, Green MM (1981) Thirdchromosome mutagen-sensitive mutants of Drosophila melanogaster. Genetics 97:607-623. Medline

Bozdagi O, Sakurai T, Papapetrou D, Wang X, Dickstein DL, Takahashi N, Kajiwara Y, Yang M, Katz AM, Scattoni ML, Harris MJ, Saxena R, Silverman JL, Crawley JN, Zhou Q, Hof PR, Buxbaum JD (2010) Haploinsufficiency of the autism-associated Shank3 gene leads to deficits in synaptic function, social interaction, and social communication. Mol Autism 1:15. CrossRef Medline

Brand AH, Perrimon N (1993) Targeted gene expression as a means of altering cell fates and generating dominant phenotypes. Development 118 : 401-415. Medline

Chen CM, Strapps W, Tomlinson A, Struhl G (2004) Evidence that the cysteine-rich domain of Drosophila Frizzled family receptors is dispensable for transducing Wingless. Proc Natl Acad Sci U S A 101: 15961-15966. CrossRef Medline

Cook RK, Christensen SJ, Deal JA, Coburn RA, Deal ME, Gresens JM, Kaufman TC, Cook KR (2012) The generation of chromosomal deletions to provide extensive coverage and subdivision of the Drosophila melanogaster genome. Genome Biol 13:R21. CrossRef Medline

DiAntonio A, Petersen SA, Heckmann M, Goodman CS (1999) Glutamate receptor expression regulates quantal size and quantal content at the Drosophila neuromuscular junction. J Neurosci 19:3023-3032. Medline

Dickins EM, Salinas PC (2013) Wnts in action: from synapse formation to synaptic maintenance. Front Cell Neurosci 7:162. CrossRef Medline

Durand CM, Betancur C, Boeckers TM, Bockmann J, Chaste P, Fauchereau F, Nygren G, Rastam M, Gillberg IC, Anckarsäter H, Sponheim E, GoubranBotros H, Delorme R, Chabane N, Mouren-Simeoni MC, de Mas P, Bieth E, Rogé B, Héron D, Burglen L, Gillberg C, Leboyer M, Bourgeron T (2007) Mutations in the gene encoding the synaptic scaffolding protein SHANK3 are associated with autism spectrum disorders. Nat Genet 39: 25-27. CrossRef Medline

Failla P, Romano C, Alberti A, Vasta A, Buono S, Castiglia L, Luciano D, Di Benedetto D, Fichera M, Galesi O (2007) Schizophrenia in a patient with subtelomeric duplication of chromosome 22q. Clin Genet 71:599-601. CrossRef Medline

Fujita SC, Zipursky SL, Benzer S, Ferrús A, Shotwell SL (1982) Monoclonal antibodies against the Drosophila nervous system. Proc Natl Acad Sci U S A 79:7929-7933. CrossRef Medline

Grabrucker AM, Schmeisser MJ, Schoen M, Boeckers TM (2011) Postsynaptic ProSAP/Shank scaffolds in the cross-hair of synaptopathies. Trends Cell Biol 21:594-603. CrossRef Medline

Groth AC, Fish M, Nusse R, Calos MP (2004) Construction of transgenic Drosophila by using the site-specific integrase from phage phiC31. Genetics 166:1775-1782. CrossRef Medline

Guilmatre A, Huguet G, Delorme R, Bourgeron T (2014) The emerging role of SHANK genes in neuropsychiatric disorders. Dev Neurobiol 74: 113-122. CrossRef Medline

Han K, Holder JL Jr, SchaafCP, Lu H, Chen H, Kang H, TangJ, Wu Z, Hao S, Cheung SW, Yu P, Sun H, Breman AM, Patel A, Lu HC, Zoghbi HY (2013) SHANK3 overexpression causes manic-like behaviour with unique pharmacogenetic properties. Nature 503:72-77. CrossRef Medline

Hung AY, Futai K, Sala C, Valtschanoff JG, Ryu J, Woodworth MA, Kidd FL, Sung CC, Miyakawa T, Bear MF, Weinberg RJ, Sheng M (2008) Smaller dendritic spines, weaker synaptic transmission, but enhanced spatial learning in mice lacking Shank1. J Neurosci 28:1697-1708. CrossRef Medline

Jiang YH, Ehlers MD (2013) Modeling autism by SHANK gene mutations in mice. Neuron 78:8-27. CrossRef Medline

Kalkman HO (2012) A review of the evidence for the canonical Wnt pathway in autism spectrum disorders. Mol Autism 3:10. CrossRef Medline

Kouser M, Speed HE, Dewey CM, Reimers JM, Widman AJ, Gupta N, Liu S, Jaramillo TC, Bangash M, Xiao B, Worley PF, Powell CM (2013) Loss of predominant Shank3 isoforms results in hippocampusdependent impairments in behavior and synaptic transmission. J Neurosci 33:18448-18468. CrossRef Medline

Lahey T, Gorczyca M, Jia XX, Budnik V (1994) The Drosophila tumor suppressor gene dlg is required for normal synaptic bouton structure. Neuron 13:823-835. CrossRef Medline

Liebl FL, Featherstone DE (2008) Identification and investigation of Drosophila postsynaptic density homologs. Bioinform Biol Insights 2:369381. Medline

Ling D, Salvaterra PM (2011) Robust RT-qPCR data normalization: validation and selection of internal reference genes during post-experimental data analysis. PLoS One 6:e17762. CrossRef Medline

Livak KJ, Schmittgen TD (2001) Analysis of relative gene expression data using real-time quantitative PCR and the 2(-Delta Delta $\mathrm{C}(\mathrm{T})$ ) method. Methods 25:402-408. CrossRef Medline

Marrus SB, Portman SL, Allen MJ, Moffat KG, DiAntonio A (2004) Differential localization of glutamate receptor subunits at the Drosophila neuromuscular junction. J Neurosci 24:1406-1415. CrossRef Medline

Mathew D, Ataman B, Chen J, Zhang Y, Cumberledge S, Budnik V (2005) Wingless signaling at synapses is through cleavage and nuclear import of receptor DFrizzled2. Science 310:1344-1347. CrossRef Medline

McVey M, Andersen SL, Broze Y, Sekelsky J (2007) Multiple functions of Drosophila BLM helicase in maintenance of genome stability. Genetics 176:1979-1992. CrossRef Medline

Metaxakis A, Oehler S, Klinakis A, Savakis C (2005) Minos as a genetic and genomic tool in Drosophila melanogaster. Genetics 171:571-581. CrossRef Medline

Miech C, Pauer HU, He X, Schwarz TL (2008) Presynaptic local signaling by a canonical wingless pathway regulates development of the Drosophila neuromuscular junction. J Neurosci 28:10875-10884. CrossRef Medline

Moessner R, Marshall CR, Sutcliffe JS, Skaug J, Pinto D, Vincent J, Zwaigenbaum L, Fernandez B, Roberts W, Szatmari P, Scherer SW (2007) Contribution of SHANK3 mutations to autism spectrum disorder. Am J Hum Genet 81:1289-1297. CrossRef Medline

Mosca TJ, Schwarz TL (2010) The nuclear import of Frizzled2-C by Importins-beta11 and alpha2 promotes postsynaptic development. Nat Neurosci 13:935-943. CrossRef Medline

Packard M, Koo ES, Gorczyca M, Sharpe J, Cumberledge S, Budnik V (2002) The Drosophila Wnt, wingless, provides an essential signal for pre- and postsynaptic differentiation. Cell 111:319-330. CrossRef Medline

Parnas D, Haghighi AP, Fetter RD, Kim SW, Goodman CS (2001) Regulation of postsynaptic structure and protein localization by the Rho-type guanine nucleotide exchange factor dPix. Neuron 32:415-424. CrossRef Medline

Peça J, Feliciano C, Ting JT, Wang W, Wells MF, Venkatraman TN, Lascola CD, Fu Z, Feng G (2011) Shank3 mutant mice display autistic-like be- 
haviours and striatal dysfunction. Nature 472:437-442. CrossRef Medline

Ranganayakulu G, Schulz RA, Olson EN (1996) Wingless signaling induces nautilus expression in the ventral mesoderm of the Drosophila embryo. Dev Biol 176:143-148. CrossRef Medline

Roussignol G, Ango F, Romorini S, Tu JC, Sala C, Worley PF, Bockaert J, Fagni L (2005) Shank expression is sufficient to induce functional dendritic spine synapses in aspiny neurons. J Neurosci 25:3560-3570. CrossRef Medline

Rubin GM, Hong L, Brokstein P, Evans-Holm M, Frise E, Stapleton M, Harvey DA (2000) A Drosophila complementary DNA resource. Science 287:2222-2224. CrossRef Medline

Schindelin J, Arganda-Carreras I, Frise E, Kaynig V, Longair M, Pietzsch T, Preibisch S, Rueden C, Saalfeld S, Schmid B, Tinevez JY, White DJ, Hartenstein V, Eliceiri K, Tomancak P, Cardona A (2012) Fiji: an opensource platform for biological-image analysis. Nat Methods 9:676-682. CrossRef Medline

Schmeisser MJ, Ey E, Wegener S, Bockmann J, Stempel AV, Kuebler A, Janssen AL, Udvardi PT, Shiban E, Spilker C, Balschun D, Skryabin BV, Dieck St, Smalla KH, Montag D, Leblond CS, Faure P, Torquet N, Le Sourd AM, Toro R, Grabrucker AM, Shoichet SA, Schmitz D, Kreutz MR, Bourgeron T, Gundelfinger ED, Boeckers TM (2012) Autistic-like behaviours and hyperactivity in mice lacking ProSAP1/Shank2. Nature 486:256-260. CrossRef Medline

Schmid A, Hallermann S, Kittel RJ, Khorramshahi O, Frölich AM, Quentin C, Rasse TM, Mertel S, Heckmann M, Sigrist SJ (2008) Activity-dependent site-specific changes of glutamate receptor composition in vivo. Nat Neurosci 11:659-666. CrossRef Medline

Sheng M, Kim E (2000) The Shank family of scaffold proteins. J Cell Sci 113:1851-1856. Medline

Sheng M, Kim E (2011) The postsynaptic organization of synapses. Cold Spring Harb Perspect Biol 3:a005678. CrossRef Medline

Shiga Y, Tanaka-Matakatsu M, Hayashi S (1996) A nuclear GFP/betagalactosidase fusion protein as a marker for morphogenesis in living Drosophila. Dev Growth Differ 38:99-106. CrossRef

Sievers F, Wilm A, Dineen D, Gibson TJ, Karplus K, Li W, Lopez R, McWilliam H, Remmert M, Söding J, Thompson JD, Higgins DG (2011) Fast, scalable generation of high-quality protein multiple sequence alignments using Clustal Omega. Mol Syst Biol 7:539. CrossRef Medline

Speed HE, Kouser M, Xuan Z, Reimers JM, Ochoa CF, Gupta N, Liu S, Powell CM (2015) Autism-associated insertion mutation (InsG) of Shank3 exon 21 causes impaired synaptic transmission and behavioral deficits. J Neurosci 35:9648-9665. CrossRef Medline

Speese SD, Ashley J, Jokhi V, Nunnari J, Barria R, Li Y, Ataman B, Koon A,
Chang YT, Li Q, Moore MJ, Budnik V (2012) Nuclear envelope budding enables large ribonucleoprotein particle export during synaptic Wnt signaling. Cell 149:832-846. CrossRef Medline

Takeuchi M, Hata Y, Hirao K, Toyoda A, Irie M, Takai Y (1997) SAPAPs. A family of PSD-95/SAP90-associated proteins localized at postsynaptic density. J Biol Chem 272:11943-11951. CrossRef Medline

Tapia JC, Kasthuri N, Hayworth KJ, Schalek R, Lichtman JW, Smith SJ, Buchanan J (2012) High-contrast en bloc staining of neuronal tissue for field emission scanning electron microscopy. Nat Protoc 7:193-206. CrossRef Medline

Uchino S, Waga C (2013) SHANK3 as an autism spectrum disorderassociated gene. Brain Dev 35:106-110. CrossRef Medline

Uemura T, Mori H, Mishina M (2004) Direct interaction of GluR $\delta 2$ with Shank scaffold proteins in cerebellar Purkinje cells. Mol Cell Neurosci 26:330-341. CrossRef Medline

Verpelli C, Dvoretskova E, Vicidomini C, Rossi F, Chiappalone M, Schoen M, Di Stefano B, Mantegazza R, Broccoli V, Böckers TM, Dityatev A, Sala C (2011) Importance of Shank3 protein in regulating metabotropic glutamate receptor 5 (mGluR5) expression and signaling at synapses. J Biol Chem 286:34839-34850. CrossRef Medline

Verpelli C, Schmeisser MJ, Sala C, Boeckers TM (2012) Scaffold proteins at the postsynaptic density. Adv Exp Med Biol 970:29-61. CrossRef Medline

Wagh DA, Rasse TM, Asan E, Hofbauer A, Schwenkert I, Dürrbeck H, Buchner S, Dabauvalle MC, Schmidt M, Qin G, Wichmann C, Kittel R, Sigrist SJ, Buchner E (2006) Bruchpilot, a protein with homology to ELKS/ CAST, is required for structural integrity and function of synaptic active zones in Drosophila. Neuron 49:833-844. CrossRef Medline

Wang X, McCoy PA, Rodriguiz RM, Pan Y, Je HS, Roberts AC, Kim CJ, Berrios J, Colvin JS, Bousquet-Moore D, Lorenzo I, Wu G, Weinberg RJ, Ehlers MD, Philpot BD, Beaudet AL, Wetsel WC, Jiang YH (2011) Synaptic dysfunction and abnormal behaviors in mice lacking major isoforms of Shank3. Hum Mol Genet 20:3093-3108. CrossRef Medline

Witsell A, Kane DP, McVey M (2010) Super-sized deletions: improved transposon excision screens using a mus309 mutant background. Fly (Austin) 4:137-140. Medline

Won H, Lee HR, Gee HY, Mah W, Kim JI, Lee J, Ha S, Chung C, Jung ES, Cho YS, Park SG, Lee JS, Lee K, Kim D, Bae YC, Kaang BK, Lee MG, Kim E (2012) Autistic-like social behaviour in Shank2-mutant mice improved by restoring NMDA receptor function. Nature 486:261-265. CrossRef Medline

Zipursky SL, Venkatesh TR, Teplow DB, Benzer S (1984) Neuronal development in the Drosophila retina: monoclonal antibodies as molecular probes. Cell 36:15-26. CrossRef Medline 